\title{
A CENTRIFUGE STUDY ON THE INFLUENCE OF TUNNEL EXCAVATION ON PILES IN SAND
}

\author{
Geyang. Song ${ }^{1}$ and Alec M. Marshall ${ }^{2}$ \\ ${ }^{1}$ Research Fellow, Faculty of Engineering, University of Nottingham, Nottingham, UK. \\ Email: geyang.song1@nottingham.ac.uk \\ ${ }^{2}$ Associate Professor, Faculty of Engineering, University of Nottingham, Nottingham, UK. \\ Email: alec.marshall@ nottingham.ac.uk
}

\begin{abstract}
Tunnelling induced ground movements can affect the equilibrium state of an existing pile, causing uneven settlement among pile groups and damage to connected structures. This paper presents results from five centrifuge tests aimed at evaluating the load redistribution mechanisms that occur within piles located close to tunnel excavation. Two main mechanisms are studied: firstly, those related to ground displacements and stress relief related to tunnelling; and secondly, those related to pile head load changes caused by connected superstructures (accomplished using a hybrid centrifuge-numerical modelling method). A novel fibre Bragg grating sensor system was used to measure shaft shear stresses along model piles. Results are used to quantify the relative impact that these two mechanisms have on pile load redistribution during tunnel volume loss. In addition, post-tunnelling pile loading tests were performed, with results indicating that tunnelling induced ground volumetric strains could influence the post-tunnelling loading response of piles.
\end{abstract}

Keywords: tunnel, pile, structure, centrifuge 


\section{INTRODUCTION}

Tunnel construction frequently takes place close to, and in some cases even clashes with, existing piled foundations. Ground movements and stress relief associated with tunnel construction can affect the equilibrium state of an existing pile, cause uneven settlements among pile groups, and potentially lead to damage of connected systems/structures. Therefore, it is important to understand the influence of tunnelling on pile resistance.

For displacement piles, resistance is distributed between the pile shaft (shaft resistance) and tip (end-bearing load); it is therefore important to understand the pile shaft shearing mechanism and load transfer between the shaft and tip during pile jacking as well as tunnel excavation.

For jacked (displacement) piles, as suggested by Boulon and Foray (1986), the pile shaft shearing mechanism during pile jacking is intermediate between constant normal load and constant volume conditions, and can be modelled by a spring normal to the interface, i.e. a constant normal stiffness (CNS) condition. The CNS condition has been widely used in direct shear and ring shear tests to study pile shaft resistance degradation (Kelly, 2001; Evgin and Fakharian, 1997; Tabucanon et al., 1995; Porcino et al., 2003; Mortara et al., 2010; DeJong et al., 2003). However, centrifuge tests conducted by Lehane et al. (2005) suggested that, for displacement piles, the normal stiffness decreases during shearing. Therefore, the CNS test can only approximate the pile shaft shearing response.

Centrifuge testing has been widely accepted as a tool to investigate pile shaft shearing mechanisms (Bruno, 1999; Nicola and Randolph, 1999; Klotz and Coop, 2001; White and Lehane, 2004). In recent years, tunnel-pile-structure-interaction (TPSI) problems have been investigated using geotechnical centrifuge testing (Loganathan et al., 2000; Jacobsz, 2003; Lee and Chiang, 2007; Marshall and Mair, 2011; Franza et al., 2019). In these centrifuge tests, individual piles or a group of piles connected to a rigid pile cap have been used to investigate tunnel-pile interaction mechanisms during tunnelling, neglecting the effect of a connected structure, which may impact the load transfer between piles during tunnel volume loss, therefore changing an individual pile's resistance or load distribution. Only a few centrifuge tests have been done to study changes in pile 
resistance due to nearby tunnel excavation in which the piles are connected to a structure, where the effect of structure stiffness is considered (Franza and Marshall, 2018).

In this paper, data from five centrifuge tests in dry silica sand are presented to investigate load transfer mechanisms along piles during pile jacking and, subsequently, during tunnel volume loss. The effect of a connected 5-storey framed structure was considered during the tunnel volume loss process (resulting in changes to pile head load) using the coupled centrifuge-numerical modelling (CCNM) technique (Idinyang et al., 2018; Franza and Marshall, 2018). Shaft shear strain/force profiles along the model piles were measured using a novel fibre Bragg grating sensor system (Song et al., 2019). In addition, post-tunnelling pile jacking tests were conducted to study the effect of tunnelling on pile shaft resistance, pile load capacity, and stiffness.

\section{EXPERIMENTAL SETUP}

\section{Introduction}

Five centrifuge tests were conducted on the University of Nottingham Centre for Geomechanics (NCG) $2 \mathrm{~m}$ radius, $50 \mathrm{~g}$-tonne geotechnical centrifuge at an acceleration of 80 times gravity (i.e. $80 \mathrm{~g}$ ); Table 1 summarises the tests. Figure 1 shows the layout of the test geometry for (a) the pile jacking (PJ) test, and (b) the tunnel-pile interaction tests, including details of the structural configuration.

The pile jacking test was conducted to assess ultimate pile capacity and investigate the development of pile shaft resistance where tunnelling induced ground movements were not included. In the pile jacking test, four piles, initially installed at $1 \mathrm{~g}$ to a depth of $140 \mathrm{~mm}$, were driven by a distance of $\approx 2.2 \mathrm{~mm}(\approx 0.2$ times pile diameter $)$ at $80 \mathrm{~g}$.

The tunnel-pile interaction tests include one tunnel-pile group interaction (TPGI) test and three tunnel-pile-structure interaction (TPSI) tests. In the TPGI test, the effect of tunnelling on a group of four piles was studied (geometry as in Figure 1 but with no connected structure), with a constant load applied to each pile (i.e. applied load did not vary with tunnel volume loss). The central axis of the nearest pile was separated from the tunnel axis by a distance of $d_{e}=75 \mathrm{~mm}$; the pile tips were at a depth $L_{p}=140 \mathrm{~mm}$, giving a clear vertical distance to the depth of the tunnel crown of 
$22 \mathrm{~mm}$. The pile-pile separation (between central axes) was $S_{p}=75 \mathrm{~mm}$ in all tunnelling tests, whereas $S_{p}$ was $150 \mathrm{~mm}$ in the pile jacking test. In the TPSI tests, labelled as test TPSI, 2 and 3, the same geometric scenario as the TPGI test was considered, except that in these tests the load applied to the piles was adjusted during tunnel volume loss according to the load redistribution of a connected 5-story steel frame structure (accomplished using the CCNM technique (Idinyang et al., 2018; Franza and Marshall, 2018)). The three TPSI tests differed only in terms of final tunnel volume loss $V_{l, t f}: V_{l, t f}=2.2 \%$ for TPSI1, $V_{l, t f}=3.2 \%$ for TPSI2, and $V_{l, t f}=2.8 \%$ for TPSI3. Test TPSI3 also included the use of cameras to capture soil displacements at a transparent acrylic wall of the centrifuge strongbox which, located a distance of $75 \mathrm{~mm}$ (in the direction of the tunnel) from the central axis of the row of piles.

\section{Centrifuge model}

The centrifuge strong box used for testing had internal dimensions of $150 \mathrm{~mm}$ width, $700 \mathrm{~mm}$ length, and a height of either $400 \mathrm{~mm}$ (TPSI1 and TPSI2) or $700 \mathrm{~mm}$ (TPSI3; a modified strongbox was used for this test). An eccentric rigid boundary mechanical (eRBM) model tunnel was used (Song et al., 2018; Song and Marshall, 2020) to simulate tunnel volume loss. The model tunnel contains a single bi-directional screw shaft with two hexagonal wedge-shaped shafts (fixed into the bi-directional ball screw flange nuts) that control the position of six segments that form the tunnel boundary. Tunnel volume loss is achieved by rotating the bi-directional screw shaft (driven by a stepper motor and gearbox), which causes the six tunnel segments to move towards the tunnel centreline. The two wedged-shaped shafts have six surfaces, with taper angle varying from $4^{\circ}$ at the tunnel crown to $0^{\circ}$ at the tunnel invert, creating an eccentric ground loss distribution around the tunnel (ground loss displacements decreasing from crown to invert). A detailed description of the model tunnel configuration is provided in Song et al. (2018); Song and Marshall (2020). The model tunnel has an initial diameter of $D_{t}=90 \mathrm{~mm}$ and was buried with a cover of $C=162 \mathrm{~mm}$, giving $C / D_{t}=1.8$.

The coupled centrifuge-numerical modelling (CCNM) technique (Franza et al., 2016; Idinyang et al., 2018) was used to incorporate the effect of the steel frame structure in the centrifuge tests. 
In the TPSI tests, the tunnel, soil and piles are simulated in the centrifuge model (geotechnical domain), and the structure is simulated in a numerical simulation (structural domain). The real-time data interface developed by Idinyang et al. (2018) is used to share pile load $\left(P_{i}\right)$ and displacement $\left(v_{i}\right)$ data between the two domains; the subscripts denote the pile number (refer to Figure 1). The CCNM modelling process can be summarised as follows (illustrated in Figure 2, with numbered stages relating to details given here):

1. In the centrifuge, the initial pile head load $\left(P_{i}\right)$ for each pile is applied by the load-controlled actuators, which is determined by the structure's self-weight. One increment of tunnel volume loss $\left(\Delta V_{l, t} \approx 0.1 \%\right.$ in these tests $)$ is achieved using the eRBM model tunnel.

2. The ground movements due to tunnel volume loss cause settlement of the piles $\left(v_{i}\right)$.

3. The pile displacement data $\left(v_{i}\right)$ are transferred to the numerical model through the real-time data interface.

4. Based on the pile displacement data $v_{i}$, the numerical model calculates the modified pile head loads $\left(P_{i}^{\prime}\right)$.

5. The modified loads $P_{i}^{\prime}$ are then fed back into the centrifuge model through the real-time data interface, and the pile head loads are adjusted to the modified values using the loadcontrolled actuators. This process continues to cycle (steps 2-5) until a steady-state is reached, determined as the time when $\Delta P$ is less than a specific value $\left(\Delta P=P_{i}^{\prime}-P_{i}\right)$. To minimise the cycling time, small increments of tunnel volume loss are used.

6. Once a steady-state is reached, tunnel volume loss is incremented again, and the above process is repeated (steps 1-6).

\section{Numerical model of the steel frame structure}

The numerical model for the structure was developed using ABAQUS (Hibbitt, 2002), simulating a five-storey steel frame building designed for storage and machine plant use. Building elements such as stairways, facades, and bracings were not considered in the structural model. A 
linear elastic constitutive model was used for the frame with Young's modulus $E=2.1 \times 10^{11} \mathrm{~N} / \mathrm{m}^{2}$ in prototype scale and a Poisson's ratio of $\mu=0.3$. The dimensions of the steel frame building as well as column and beam sizes are given in Figure 1 (prototype scale). The variable load applied to the building was based on Eurocode specifications (Gulvanessian et al., 2009) for storage buildings $\left(7.5 \mathrm{kN} / \mathrm{m}^{2}\right)$, and the permanent load was $3 \mathrm{kN} / \mathrm{m}^{2}$, giving a total load of $2364 \mathrm{kN}$ for the two inner piles and $1630 \mathrm{kN}$ for the two outer piles (prototype scale). These were the initial pile loads in the TPSI tests; in the TPGI test, these pile loads were maintained throughout the tunnel volume loss process.

\section{Model piles}

In practice, a $0.8 \mathrm{~m}$ diameter concrete pile has an axial stiffness $E A=(10-14) \times 10^{3} \mathrm{MN}$, assuming concrete has a Young's modulus $E$ ranging from 20-28 GPa. To match the diameter of the pile (using a nominal centrifuge acceleration of $80 \mathrm{~g}$ ), a $10 \mathrm{~mm}$ diameter aluminium hollow tube was used. The thickness of the model tube was $1 \mathrm{~mm}$, which gives an axial rigidity $E A=19.4 \times 10^{3} \mathrm{MN}$ in prototype scale (slightly higher than the $0.8 \mathrm{~m}$ full-scale concrete pile).

The soil-pile interface plays an important role in determining the pile shaft shear stress mechanism. In reality, the interface will lie somewhere between perfectly smooth and rough, however accurate replication of this interface in centrifuge models is very challenging, and attempts to do so will incur uncertainties in the interpretation of results. As a result, it was decided to model a perfectly rough soil-pile interface in these tests by bonding sand to the surface and tip of the model piles (the same sand used for soil body; consistent with Franza and Marshall (2018)), giving a final pile diameter of $d_{p}=11 \mathrm{~mm}$.

\section{Pile strain measurement with FBG sensors}

To assess pile shaft shear stress profiles or mechanisms, strain gauges are commonly used to measure the axial strains along model piles, which is then converted to force assuming linear elastic model pile response. Conventional strain gauges can be difficult to install on miniature models used within centrifuge tests. Model piles are typically $8-12 \mathrm{~mm}$ in diameter, making the installation of strain gauges on the inside of hollow-tube model piles challenging. Therefore, strain gauges are 
normally bonded on the outer surface of model piles, which can create an irregular outer surface and necessitate the change of pile surface roughness. Moreover, the quality of the strain gauge output signal is affected by the complex electromagnetic field within a geotechnical centrifuge. Another option for measuring strain comes from using optical Fibre Bragg Grating (FBG) sensors (Correia et al., 2016). The basic principle of the FBG sensor is to measure the shift in wavelength of light of the returned "Bragg" due to strain or temperature changes in the optical fibre (Kersey et al., 1997; Moyo et al., 2005). Unlike conventional strain gauges, optical fibre sensors are immune to the effects of electromagnetic fields. In addition, FBG sensors are relatively small and light, which has benefits for small-scale centrifuge testing.

The FBG system adopted in this study is shown in Figure 3. A four-channel commercial FBG interrogator (CASSTK SAI-1122PF) capable of scanning wavelengths of 1525-1565 nm at a frequency of $2 \mathrm{~Hz}$ was used. The FBG interrogator was mounted in the centrifuge data acquisition systems (DAS) cabinet and exposed to g-levels of 4-7 g during tests (where the soil model experienced a nominal $80 \mathrm{~g}$ ). The data measured from the FBG interrogator was transferred to the on-board gigabit switch 1 (the switches are numbered in Figure 3) which, along with all the other digitised data, is transferred through the fibre optic rotary joint to the gigabit switch 2 located in the control room. This setup enables real time logging of FBG data from the control room during centrifuge tests. To measure the axial force distribution, FBG sensors were installed along opposing inner surfaces of the hollow aluminium tubes used for the model piles. The FBG sensors were made from a single-mode optical fibre. Each fibre contains three FBG sensors written by an excimer laser (reflectivity of $90 \%$ ) with a centre wavelength of 1530,1535 , and $1540 \mathrm{~nm}$ or 1545,1550 , and $1560 \mathrm{~nm}$. Thus, three axial force measurements were made along each pile, denoted as S1, S2, and S3, as shown in Figure 3. One additional FBG sensor (not located on the model piles) was used to measure the change in temperature during centrifuge tests, which will also cause straining of the model piles due to thermal expansion/contraction. Results indicated that, during the centrifuge tests, the maximum change in ambient temperature was around $0.8^{\circ} \mathrm{C}$ (for the duration of the centrifuge tests); additional testing has shown that, within hollow aluminium model 
piles embedded in the sand, a temperature change of about $0.3^{\circ} \mathrm{C}$ can be expected. The variation in axial force caused by this temperature change is less than $12 \mathrm{~N}$ in model scale; this variation does not affect the shaft resistance calculation (a difference in axial force along the pile) presented later, which is the main focus of this paper.

The model piles were calibrated on a loading frame (within a temperature controlled room), obtaining a linear relationship (calibration factor) between FBG wavelength shift and applied load. For interpreting centrifuge test results, at a given depth along the pile, the average of readings from two opposing FBG sensors was used to calculate the axial force of the pile at that location (for example, for measurement point $\mathrm{S} 1$, the axial force was obtained from $\mathrm{FBG}_{1}$ and $\mathrm{B}_{4}$; see Figure 3).

\section{Soil model and preparation}

Fine-grained silica sand commonly knows as Leighton Buzzard Fraction E sand was used for the tests, with a typical average diameter $D_{50}$ of $0.14 \mathrm{~mm}$ and a specific gravity $G_{s}$ of 2.65 . The sand has a maximum $\left(e_{\max }\right)$ and minimum $\left(e_{\min }\right)$ void ratio of 1.01 and 0.61 , respectively, and a coefficient of uniformity $C_{u}$ of 1.58 . The model was prepared using dry sand pouring, achieving a relative density in all tests of $I_{d} \approx 90 \%$, giving a density of $\approx 1603 \mathrm{~kg} / \mathrm{m}^{3}$.

To prepare the model, the tunnel was secured within the back wall of the strongbox, which was laid flat such that the model tunnel was oriented upwards. This allowed the sand to be poured in the direction of the tunnel longitudinal axis, consistent with Vorster (2006); Marshall (2009); Zhou (2015); Franza (2016) and Farrell (2010). For test TPSI3, after sand pouring, a thin layer of dyed sand was placed uniformly on the top surface of the sample to improve analysis of digital images taken through the front acrylic wall, which were used to track soil movements using particle image velocimetry (PIV) (Stanier et al., 2015). The front acrylic window was then bolted to the strongbox, which was then rotated to its upright position. All four piles were pushed into the sand at $1 \mathrm{~g}$, starting with the pile closest to the tunnel and moving outwards. A support frame was used to ensure the piles were pushed vertically, which was temporarily connected to the strongbox sidewall. Once all the piles were installed to the designated position and depth, the support frame 
was disassembled. The pile loading system was then fixed to the top of the strongbox, and the model piles were connected to the linear actuators. The tunnel volume loss control system (gearbox and stepper motor) and linear variable differential transformers (LVDTs) were then installed (see Figure 2, and refer to Song (2019) for full details).

\section{Testing procedures}

A constant $5 \mathrm{~N}$ vertical load (model scale) was maintained at the pile head (using the actuators under load controlled settings) during centrifuge spin-up to $80 \mathrm{~g}$. This was done to ensure minimum relative displacement occurred between the soil and the piles during centrifuge spin-up (if fixed in place during spin-up, the soil would settle more than the pile). Three stabilisation cycles (going from $80 \mathrm{~g}$ to $10 \mathrm{~g}$ and back to $80 \mathrm{~g}$ ) were performed to encourage a uniform stress distribution within the soil body and to improve repeatability between tests. The piles were then loaded to the designated working load ( $255 \mathrm{~N}$ for outer piles 1 and 4 , and $370 \mathrm{~N}$ for inner piles 2 and 3; refer to pile numbering in Figure 1) in $50 \mathrm{~N}$ stages, starting with pile 1 and moving sequentially to pile 4.

For the tunnel-pile group interaction TPGI test, these initial loads were maintained throughout the volume loss process. For the TPSI tests using the CCNM technique, the real-time interface was then activated, followed by the initiation of ABAQUS (simulating the steel frame structure). This final step gives control of the pile loads in the centrifuge to the ABAQUS program, which takes in measurements of pile displacements from the centrifuge and outputs new pile loads based on the outcomes of the structural numerical simulation; the pile loads were then passed back to the control system, and the load on the piles was adjusted accordingly. The tunnel volume loss $\left(V_{l, t}\right)$ process was then started, increasing up to $V_{l, t} \approx 2.2 \%, 3.2 \%$, and $2.8 \%$ for tests TPSI1, TPSI2 and TPSI3, respectively. The tunnel volume loss increment was approximately $0.1 \%$ in all tests. For test TPSI3, two cameras were used to take images after every tunnel volume loss increment. After reaching the stated maximum tunnel volume loss, the piles were jacked into the soil, starting from pile 1 and proceeding to pile 4. The actuator jacking speed was set to $0.1 \mathrm{~mm} / \mathrm{s}$, however due to the effect of a spring used within the actuators to dampen the load application rate, the pile jacking speed varied somewhat (this would not affect results for these tests in dry sand). Once the 
pile settlement was greater than $20 \%$ of the pile diameter $\left(0.2 d_{p}\right)$, the pile jacking procedure was terminated.

For the pile jacking (PJ) test (no model tunnel included), after the stabilisation cycles, the piles were jacked into the soil using the same procedure described above. The pile jacking sequence was pile number 2-4-3-1 (see Figure 1(a)). To reduce the pile-pile interaction effect during pile jacking, the pile spacing in this test was $S_{p}=150 \mathrm{~mm}$ (pile spacing in tunnelling tests was $S_{p}=75 \mathrm{~mm}$ ).

\section{RESULTS: PRE-TUNNEL VOLUME LOSS}

\section{Pile load distribution during centrifuge spin-up}

Before considering the influence of tunnel excavation on pile load distribution in detail, it is of interest to investigate the effect of the increased self-weight of the soil in the centrifuge on the pile load distribution (i.e. the effect of centrifuge spin-up).

As previously mentioned, the model piles were pushed into the soil at $1 \mathrm{~g}$ and $5 \mathrm{~N}$ load was applied to the top of the piles during centrifuge spin-up. At $1 \mathrm{~g}$, the shaft resistance along the piles and the stationary radial effective stress $\left(\sigma_{r}^{\prime}\right)$ are assumed to be minimal. During centrifuge spin-up, the piles and the surrounding soil tend to settle because of the increase in self-weight. Figure 4 presents the axial force along the pile after centrifuge spin-up from all the centrifuge tests; a $5 \mathrm{~N}$ load at a distance of $30 \mathrm{~mm}$ above the soil surface corresponds to the location of the load cell above each pile. The dotted grey line represents the theoretical axial force along the pile due to self-weight of the pile only (neglecting pile-soil interface resistance). Figure 4 shows that the axial force measured from the FBG sensors was greater than the self-weight of the piles. It is inferred that this offset in axial force distribution along the pile was caused by the mobilised shaft resistance (the relative movement between the pile and the surrounding soil during centrifuge spin-up).

The results in Figure 4 indicate that the axial force tends to show proportionally high increases (in relation to the theoretical force due to self-weight) within the upper and middle portions of the piles ( $0-85 \mathrm{~mm}$ below soil surface), whereas in many cases this proportional increase was less in the lower portion of the piles (85-130 mm below the soil surface). Figure 5(a) shows the soil displacement profile at the acrylic wall after centrifuge acceleration for test TPSI3. Note that soil 
displacements measured at the acrylic wall do not represent the soil movements around the piles since the piles were located at the middle of the strong box width $(75 \mathrm{~mm}$ from the front acrylic wall). The measured settlements across the face of the acrylic wall were sufficiently uniform to plot the data as a single profile with depth. The increase in axial force shown in Figure 4 indicates that soil settlements around the upper and middle portions of the pile were greater than pile settlement, acting to 'pull' the pile downwards (shear forces acting downwards), thereby increasing the compressive forces in the piles at greater depth. Around the lower portion of the piles, the soil settlement was similar or less than the pile settlement, hence the increase in axial force with depth was mainly due to the pile's self-weight, see illustration in Figure 5 (b) and (c).

To further understand the effect of centrifuge spin-up on pile shaft resistance, it is necessary to evaluate the stationary radial effective stress $\left(\sigma_{r}^{\prime}\right)$. In addition, the estimation of stationary radial effective stress could help understand the pile-soil interface stress path, which will be discussed later in the paper.

Due to the relative movement between the pile and the surrounding sand (during centrifuge spin-up), the static earth pressure coefficient $\left(K_{0}\right)$ can not be used to calculate the radial effective stress along the pile. Unfortunately, the model piles used in this study did not include radial stress cells. However, the results from Jacobsz (2003), where radial stress cells were used, may be used as a reference; the same sand was used in both studies, and the sample preparation method, soil relative density ( $I_{d}=76 \%$ for Jacobsz, $I_{d}=90 \%$ for this study), and the g-level of the tests ( $75 \mathrm{~g}$ for Jacobsz, $80 \mathrm{~g}$ in this study) were similar. The main difference between the tests was the shaft roughness, where Jacobsz (2003) left the aluminium piles untreated, and in this study the piles were coated with a layer of sand. Despite the difference in pile surface roughness, the stationary radial effective stress $\left(\sigma_{r}^{\prime}\right)$ along the pile after centrifuge spin-up from the centrifuge tests conducted by Jacobsz (2003) are used as a method to estimate $\sigma_{r}^{\prime}$ profiles for this study.

Figure 6 summarises the measured radial effective stress with depth $\left(\sigma_{r}^{\prime}\right)$ data from centrifuge tests given by Jacobsz (2003); the vertical effective stress $\left(\sigma_{v}^{\prime}\right)$ profile was calculated based on the depth of overburden. Note that all tests were done under dry conditions, so total and effective 
stresses are the same. There is a considerable amount of scatter in the measured radial effective stress data (Jacobsz (2003) reported that some radial stress cells moved slightly off-centre during installation), however by fitting a linear curve to the data (using least squares regression), the gradient of the ratio $\sigma_{r}^{\prime} / \sigma_{v}^{\prime}$ was found to be 1.46. Despite the differences in soil density and interface property between this study and the tests from Jacobsz (2003), it was assumed that this ratio of $\sigma_{r}^{\prime} / \sigma_{v}^{\prime}$ can be reasonably applied within this study.

Figure 7 shows the estimated stationary radial effective stress after centrifuge spin-up for the centrifuge tests from this study (i.e. assuming $\sigma_{r}^{\prime} / \sigma_{v}^{\prime}=1.46$ ). The differences in axial force between subsequent FBG measurement points was used to calculate the average shear stress $\left(\tau_{a v}\right)$ between the two points (see soil horizons highlighted in Figure 7). The mid-point between two FBG measurement locations is used to denote each horizon, given by $h / R=21.8,14.1$, and 5.9 , where $h$ is the distance from the horizon mid-point to the pile tip and $R$ is the radius of the model pile.

Figure 8 shows the average shear stress $\left(\tau_{a v}\right)$ versus the estimated radial effective stress $\left(\sigma_{r}^{\prime}\right)$ after centrifuge spin-up for all piles in all five tests. The critical state line was plotted based on $\phi_{c s}^{\prime}=31.4^{\circ}$, which was obtained by performing dry heap tests and triaxial tests with the sand (Song and Marshall, 2020). As previously indicated, negative shear stresses developed along the piles after centrifuge spin-up (the soil settled more than the piles). Despite the scatter in the data, the soil at horizons $h / R=21.8,14.1$ and 5.9 provide an average mobilised angle of friction of $\approx 47$, 19 , and $3^{\circ}$, respectively.

For soil horizon $h / R=21.8$, most of the data points are outside the critical state line, suggesting that peak friction angles were mobilised; note that $h / R=21.8$ is the shallowest location, hence the tendency for dilation will be high, resulting in relatively large peak friction angles (Bolton, 1986).

In addition, most of the data points in soil horizon $h / R=14.1$ and 5.9 are well within the critical state line, indicating that the shaft resistance was not fully mobilised during the centrifuge spin-up process. These results support the previous observation that, due to the relative movement between the pile and the surrounding soil, negative shaft resistance was developed (soil acting to 
'pull' the pile downwards). In addition, the mobilised friction angle decreases with depth.

The data presented in this section will be used subsequently as a reference for results obtained during pile jacking and tunnel volume loss. In addition, the estimated radial stresses along the pile will help in understanding the interface stress path during pile jacking, as will be discussed in the next subsection.

\section{Pile jacking}

In the pile jacking (PJ) test, after centrifuge spin-up, piles were jacked into the soil in the following order: 2-4-3-1 (see Figure 1a). Only FBG data from piles 2 and 3 is available (pile 4 and 1 were not instrumented during this test). As shown in the previous section, after centrifuge spin-up, the shaft resistance along the pile generally acts upwards (negative $\tau_{a v}$ value, as the soil is pulling downwards). Figure 9 plots the average shaft resistance $\tau_{a v}$ for soil horizons $h / R=5.9$, 14.1, and 21.8 versus normalised pile settlement $\left(S_{p} / d_{p}\right)$ during pile jacking; results show that shaft resistance along the piles increased during pile jacking. As expected, the deeper soil horizon $(h / R=5.9)$ experienced a greater increase and final magnitude of shear stress than the shallower soil horizons $(h / R=14.1$ and 21.8$)$ for both piles. Generally the piles showed a gradual increase in average shear stress up to $S_{p} / d_{p} \approx 8 \%$, except for pile 3 at soil horizon $h / R=5.9$, where a slight peak is observed at $S_{p} / d_{p}=6.5 \%$. After $S_{p} / d_{p} \approx 8 \%$, the average shear stresses tend towards a steady-state value.

As discussed previously, to increase the roughness of the pile interface, sand was bonded to the surface of the piles. A similar technique was adopted in the constant normal stiffens (CNS) interface shear tests conducted by Lehane et al. (2005), where the development of shear stress at a soil-soil (sand grains bonded to an aluminium surface) or soil-aluminium interface was examined. Results from Lehane et al. (2005) suggest that the ratio between critical state shear stress $\tau_{c s}$ and critical state normal stress $\sigma_{c s}^{\prime}$ is equivalent to the $\phi_{c s}^{\prime}$ value measured under triaxial conditions. Therefore, the value of $\phi_{c s}^{\prime}=31.4^{\circ}$ for the sand used in this study can be assumed as the critical state pile-soil interface angle. Based on $\phi_{c s}^{\prime}$ and the steady-state shear stress values from the left-side plots in Figure 9, the critical state radial stress $\left(\sigma_{c s}^{\prime}\right)$ can be estimated, where $\sigma_{c s}^{\prime}=\tau_{c s} / \tan \phi_{c s}^{\prime}$. 
Using estimated values of stationary radial stress $\sigma_{r}^{\prime}$ (before pile jacking) based on the previously discussed approach using results from Jacobsz (2003), a stress path of the pile-soil interface during pile jacking was estimated (using a liner path), as shown on the right-side plots in Figure 9. These results suggest that the radial stress along the pile increased during pile jacking, consistent with previous studies which have illustrated the effect of soil dilation during pile jacking (White and Bolton, 2004).

Figure 10 presents the obtained relationship between critical state radial effective stress $\sigma_{c s}^{\prime}$ and stationary radial effective stress $\sigma_{r}^{\prime}$ for both piles and shows that $\sigma_{c s}^{\prime}$ is generally 1.53 times greater than $\sigma_{r}^{\prime}$. It is known that, for rough model piles, the relatively small ratio of pile diameter to average soil grain size compared to full scale piles can exaggerate the effect of soil dilation on radial stresses acting on the pile (Boulon and Foray, 1986). To assess this effect in these tests, the obtained value of 1.53 can be compared against results from Lehane et al. (1993) where, based on a series of instrumented pile loading tests in sand, at peak shear resistance, the radial stress was approximately 1.4 times stationary values. This suggests a scaling error of less than $10 \%$, which is considered acceptable given the complex ground stress unloading that occurs during the subsequent tunnel volume loss process.

Figure 11 show the axial force distribution along the piles during pile jacking. The pile end bearing load was not measured directly; it was approximated by linearly extrapolating the data from the closest two FBG measurement points (indicated in Figure 11(a)). Results in Figure 11(a) show that end-bearing load increased with pile settlement. The increase in pile end bearing load is less than the increase in pile head load, indicating the shaft resistance mobilised, which decreased with depth for both piles 2 and 3. In addition, with pile settlement, the gradient of the axial force distribution along the middle and lower portions of the piles increased, indicating an increase in shaft resistance with depth.

The pile head load, shaft resistance, and end bearing load are plotted against pile settlement for piles 2 and 3 in Figure 11(b). With pile settlement, shaft resistance increased and reached a maximum value around $S_{p} / d_{p}=8 \%$. The pile end bearing load increased with pile settlement 
and, after about $S_{p} / d_{p}=10 \%$, the rate of increase decreased slightly. In both cases, the pile end bearing load is always greater than the pile shaft resistance.

\section{Pile loading}

For centrifuge tests TPGI and TPSI1-3, piles were loaded to the designated working load (255 N for outer piles 1 and 4; $370 \mathrm{~N}$ for inner piles 2 and 3) after centrifuge spin-up. Figure 12 shows the axial force along the piles prior to and after pile loading (only test TPSI 2 data is presented; results from other test were similar). All piles show an increase in axial force along the pile after pile head loading. Based on the estimated pile end bearing load in Figure 12, the majority of the increased pile head load was transferred to the pile shaft. After pile loading, the axial force in the upper portion of the pile $(h / R=21.8)$ shows a similar or slightly higher value than the pile head load (where pile settlement in the upper portion was not sufficient to cause reversal of shear stress direction). In all cases, there is a minimal change in shear stress along the upper portion of the pile. The axial force along the middle and lower portions of the pile $(h / R=14.1$ and 5.9$)$ decreases with depth, indicating that the shear stress is increased.

During pile loading, the radial stress along the pile is difficult to estimate because of the reversal of shear stress direction as load is applied, with soil volumetric response transitioning from contractive to dilatant. As a simplifying approach, it was assumed that the radial stress along the pile during pile loading follows the stress path presented on the right side of Figure 9 (similar to pile jacking). From the pile jacking data, it was concluded that the critical state radial effective stress $\sigma_{c s}^{\prime}$ was, on average, 1.53 times greater than the stationary radial effective stress $\sigma_{r}^{\prime}$. Therefore, for a given increase in average shear stress $\tau_{a v}$, the change in radial stress $\sigma_{r}^{\prime}$ was calculated based on the assumption that the stress path follows a straight line with a slope of $\Delta \tau_{a v} / \Delta \sigma_{r}^{\prime}=7.95$ (average gradient of the stress paths shown in Figure 9). Based on this approach, Figure 13 shows how values of average shear stress $\tau_{a v}$ increased during the pile loading stage. For the middle and lower portions of the piles, most of the shear stress values changed from negative to positive (shear stress direction changed), whereas in the upper portion, the direction remained negative. On average, however, the direction of the shear stress of the piles became positive during pile loading. In 
addition, soil horizon $h / R=5.9$ shows greater shear stress increases than soil horizon $h / R=14.1$, followed by soil horizon $h / R=21.8$, which confirms the observation mentioned above.

\section{RESULTS: RESPONSE TO TUNNEL VOLUME LOSS}

\section{Pile head load with tunnel volume loss}

In general, the pile load redistribution mechanism during tunnelling is affected by (a) tunnelling induced ground movements and stress relief, and (b) changes in pile head load due to the effect of the stiffness of a connected structure (i.e. load redistribution within the building/foundation). Before investigating pile load redistribution during tunnelling, the change in pile head load is first considered.

Figure 14 shows pile head load versus tunnel volume loss for tests TPGI and TPSI1-3. The tunnel-pile group interaction TPGI test did not consider a connected structure, hence the loadcontrolled system maintained a constant load on the piles throughout the tunnel volume loss process (the control system maintained the specified load to within $\pm 10 \mathrm{~N}$ ). For the tunnel-pile-structure interaction TPSI test series using the CCNM technique, the three tests show good consistency in pile head load variation with tunnel volume loss: pile 1 shows the most significant decrease, pile 2 shows the most significant increase, and piles 3 and 4 show less significant increases and decreases, respectively. Using test TPSI2 as an example, at $V_{l, t}=3.2 \%$, the head load of pile 1 reduced by $45 \mathrm{~N}$ (a decrease of $18 \%$ from its initial value), that of pile 2 increased by $63 \mathrm{~N}(17 \%)$, and piles 3 and 4 increased by $11 \mathrm{~N}(3 \%)$ and decreased by $28 \mathrm{~N}(3 \%)$, respectively.

To summarise, the stiffness of the structure caused load transfer between piles, where the two piles located closest to the tunnel were most affected. This load transfer will also cause changes in pile shaft resistance when compared with the TPGI test where pile load was kept constant, as discussed in the next section.

\section{Force distribution along piles after tunnel volume loss}

Tunnel volume loss will affect the pile shaft resistance and end bearing load. To maintain a balance with the pile head load (force equilibrium), additional pile settlement is required. As 
demonstrated in the previous section, pile settlement causes structure deformation (structure effect), with pile head loads changing accordingly. As mentioned earlier, pile load redistribution is affected by tunnelling induced ground movements and stress relief (referred to here as mechanism $\mathrm{T}$ for tunnelling), and load transfer between piles due to structure deformation (referred to as mechanism S for structure). To quantify the relative importance of these two mechanisms, Figure 15 plots the axial force along the depth of the piles prior to and after tunnel volume loss $\left(V_{l, t} \approx 3 \%\right)$ for tests TPGI (upper plots) and TPSI2 (lower plots). Note that, for pile 3 in test TPGI, the initial axial force at a soil depth of $40 \mathrm{~mm}$ (after pile loading) is unusual; the cause of this unusual value could not be determined. The axial force profiles are plotted by omitting the unusual readings (with dashed lines showing the trend when including these points). Though this initial reading is unusual, the changes in pile load due to tunnel volume loss, which are the main focus of this section, were sensible and were used in subsequent analyses.

For test TPGI (constant pile head load; results due solely to mechanism T), with tunnel volume loss, the end bearing load of pile 1 decreased. To balance the pile head load, pile shaft resistance increased, mainly within the lower portion. Pile 1 end bearing load is most affected by mechanism $T$ given the proximity of the pile tip to the tunnel. For pile 2 in test TPGI, pile end bearing load increased a small amount with tunnelling. This is likely a result of the gradient of tunnelling induced ground movements at the location of pile 2 (larger settlements at the surface than near the pile base) or a decrease in pile shaft resistance near the lower portion of the pile.

For pile 1 in test TPSI2, despite the decrease in pile head load due to structure stiffness (mechanism S), pile end bearing load still decreased with tunnelling. The magnitude of decrease of the end bearing load is slightly lower than the decrease in pile head load, indicating that the shaft resistance increased slightly with tunnelling. For pile 2 in test TPSI2, pile head load increased with tunnelling (mechanism S) and, consequently, the end bearing load increased. The magnitude of increase of the end bearing load in pile 2 is less than the increase in pile head load, indicating that shaft resistance took the rest of the increased pile head load.

For piles 3 and 4 in both tests (TPGI and TPSI2), the change in end bearing load and shaft 
resistance is generally less significant than piles 1 and 2 . The end-bearing load of pile 4 in test TPGI does show a small decrease, which may have been due to the effect of pile-pile interactions or boundary effects. The pile 4 head load in test TPSI 2 decreased after volume loss because of mechanism S, with a resulting reduction in the shaft resistance in the upper and middle portions of the pile.

\section{Pile shaft resistance with tunnel volume loss}

To further investigate the change in pile shaft resistance with tunnelling, Figure 16 presents the change in shear stress $\Delta \tau_{a v}$ of the piles at soil horizons $h / R=5.9,14.1$ and 21.8 with tunnel volume loss for test TPGI (on left) and TPSI2 (on right). Results from TPSI1 and TPSI3 showed good consistency with TPSI2, therefore the data are not presented.

For pile 1 in test TPGI (with constant pile head load), with tunnelling, the shaft resistance decreased in the lower portion of the pile $(h / R=5.9)$, but increased along the middle and upper portions $(h / R=14.1$ and 21.8).

For pile 1 in test TPSI2, where pile head load was shown to decrease with tunnelling (Figure 14), the response near the pile base $(h / R=5.9)$ is similar to that in test TPGI, with end-bearing resistance and shaft resistance near the base of the pile decreasing, resulting in pile settlement and redistribution of resistance to the upper portions of the pile. The response near the pile head $(h / R=21.8)$ is also similar between the two tests, hence the reducing pile head load with tunnel volume loss in test TPSI2 is mainly seen in the middle portion of the pile, with the $h / R=14.1$ response remaining relatively constant with volume loss (in contrast to the steady increasing trend for test TPGI).

For pile 2 in test TPGI, the change in shaft resistance in the middle and upper portions of the pile is minimal, however the shaft resistance reduced with tunnelling in the lower portion of the pile. For pile 2 in test TPSI2, where pile head load increased as a result of structure stiffness, the additional load caused a slight increase in shaft resistance in the middle and lower portions of the pile, and the shaft resistance in the middle portion of the pile remained relatively constant. In general, the increase in shaft resistance along the pile is not significant for pile 2 in test TPSI2. 
For pile 3 in test TPGI (constant pile head load), with tunnelling, the pile shaft resistance increased in the middle portion of the pile, but decreased in the upper and lower portions. For pile 3 in test TPSI2, the pile head load increased with tunnelling, but the shaft resistance along the pile remained relatively constant.

For pile 4 in test TPGI, the middle and upper portions of the pile show minimal change in shaft resistance. In contrast, the lower portion of the pile presents an increase in shaft resistance with tunnel volume loss. For pile 4 in test TPSI2, where pile head load decreased, shaft resistance in the middle and lower portions of the pile decreased with tunnelling, and increased in the upper portion of the pile.

To summarise, these results demonstrate and quantify not only the change in shaft resistance along piles affected by tunnelling (mechanism T), but also the effects that load redistribution within a building can have on the distribution of resistance within piles (mechanism $\mathrm{S}$ ). The contrasting results from tests TPGI and TPSI2 (tests without and with the upper structure modelled) indicate that structure stiffness (mechanism S) has an important effect on the change in pile shaft resistance with tunnelling.

\section{RESULTS: POST-TUNNELLING PILE JACKING}

One aspect of the tunnel-pile interaction scenario that has not previously been considered experimentally is the post-tunnelling pile response to loading (stiffness and capacity) and the effect that the magnitude of tunnel volume loss has on this response. The tests presented here provide the opportunity to investigate this aspect because the final tunnel volume loss $\left(V_{l, t f}\right)$ in the three TPSI tests differed $(2.2 \%, 3.2 \%$, and $2.8 \%$ for tests TPSI-1, -2 , and -3 , respectively; $3.2 \%$ for test TPGI). The piles were jacked into the soil after tunnel volume loss using the same procedure described in Section 3. Figure 17 shows the average shear stress $\tau_{a v}$ versus normalised settlement $S_{p} / d_{p}$ along the piles for soil horizons $h / R=5.9,14.1$, and 21.8 during pile jacking. Data for piles 3 and 4 in test TPGI are not available because some of the FBG signal responses went outside of the measurable range of the FBG analyser. Shear stress for soil horizon $h / R=5.1$ generally shows a greater response than soil horizon $h / R=14.9$, and shear stress for $h / R=21.8$ shows less or 
similar response to $h / R=14.9$. The average shear stresses from the three soil horizons increase with pile jacking, with values generally reaching critical state stresses $\tau_{c s}$ after about $10 \% S_{p} / d_{p}$.

As mentioned, for the TPSI tests, the final tunnel volume losses $\left(V_{l, t f}\right)$ were different. Based on the critical state shear stress $\tau_{c s}$ from Figure $17\left(\tau_{a v}\right.$ after $\left.10 \% S_{p} / d_{p}\right)$, the relationship between $\tau_{c s}$ and final tunnel volume loss $V_{l, t f}$ can be obtained, as plotted in Figure 18. In addition, greenfield pile jacking (test PJ) results are presented, where the tunnel volume loss process was not considered $\left(V_{l, t f}=0 \%\right.$; circled data in Figure 18). The relative position of the pile with respect to the tunnel is also demonstrated in Figure 18. For all three soil horizons $(h / R=5.9,14.1$, and 21.8$)$, there is no obvious relationship between $\tau_{c s}$ and pile location. In addition, with the increase in final tunnel volume loss $V_{l, t f}$, there is no obvious trend of $\tau_{c s}$ for all three soil horizons.

Figure 18 also presents the pile load capacity (pile head load at $S_{p} / d_{p}=10 \%$ ) versus final tunnel volume loss $V_{l, t f}$ (see the lower plot). Results demonstrate that there is no clear relationship between post-tunnelling pile load capacity and final tunnel volume loss. Moreover, there is no clear relationship between pile load capacity and pile location.

Despite the scatter of the results presented in Figure 18, the post-tunnelling pile jacking results from all soil horizons $(h / R=5.9,14.1$, and 21.8) generally show a similar critical state shear resistance $\tau_{c s}$ and pile head load capacity as the greenfield pile jacking test results (Test PJ).

Figure 19(a) shows the post-tunnelling load-displacement response of the piles in test TPSI in comparison to the greenfield pile jacking data (Test PJ, grey line). Note that the piles had varying magnitudes of initial load $Q_{p}$ (see subsection on pile loading), hence to get a better visualisation of the relative load-settlement response, the $\mathrm{x}$-axis is plotted as change in load $\Delta Q_{p}$. Results demonstrate that there is no appreciable difference between the initial load-settlement response of the piles in test TPSI2 and those in test PJ. The increase rate of pile head load with pile settlement can be represented by global stiffness $\left(\Delta Q_{p} / S_{p}\right)$, which is plotted in Figure 19(b) against change in pile head load $\left(\Delta Q_{p}\right)$. For a given increment of pile head load, piles from test TPSI2 show a similar global stiffness to the piles from test PJ.

To summarise, post-tunnelling pile jacking results show similar behaviour to the greenfield case 
(test PJ), both in terms of load capacity (Figure 18) and stiffness (Figure 19. This result is somewhat counter-intuitive given the implied stress relief in the yielding soil zone surrounding the tunnel and, as a result, contrasts with the analytical predictions of Marshall (2012); Marshall and Haji (2015); Marshall et al. (2020). However, as illustrated by Franza et al. (2019); Song and Marshall (2020), based on greenfield tunnelling centrifuge tests in dense sand, the majority of the soil around the tunnel (and in particular at the locations of the piles in the tests presented in this paper) experience a contractive response with tunnel volume loss. It may be that the detrimental effects of stress relief were countered by the beneficial effects of soil contraction for the tests presented here (which is not accounted for in the mentioned analytical predictions). There are likely to be other mechanisms influencing the post-tunnelling response of the piles as well which the current analyses have not explored; further work in this area is certainly warranted.

\section{CONCLUSIONS}

This paper presented data from five centrifuge tests aimed at investigating the influence of tunnel excavation on the load distribution along piles. A novel fibre Bragg grating sensor system was used to measure the shaft shear strain/force profiles along the model piles. To account for the effect of structure stiffness in the soil-structure interaction scenario, the piles were 'virtually' connected to a 5-storey framed structure using the coupled centrifuge-numerical modelling (CCNM) hybrid testing technique.

Results demonstrated that, during centrifuge spin-up, though a procedure was used to try to minimise the relative displacement of the model piles compared to the soil, negative (i.e. upwards) shear stresses developed in the mid to upper regions of the pile, caused by the drag-down action of the shallower regions of soil. The result is that the static earth pressures acting around the pile, prior to any pile loading or tunnel volume loss, are affected, with stationary radial effective stresses $\left(\sigma_{r}^{\prime}\right)$ along the pile after centrifuge spin-up estimated to be 1.46 times the vertical effective stress $\left(\sigma_{v}^{\prime}\right)$.

Pile jacking tests demonstrated that pile shaft resistance reached the steady-state value at a jacking distance of approximately $8 \%$ of the pile diameter (i.e. $S_{p} / d_{p} \approx 8 \%$ ). Results showed that 
the critical state radial effective stress $\left(\sigma_{c s}^{\prime}\right)$ was generally 1.53 times greater than the stationary radial effective stress $\left(\sigma_{r}^{\prime}\right)$.

Results were used to demonstrate two important mechanisms affecting the pile load distribution during tunnel volume loss, namely mechanism $\mathrm{T}$ related to the tunnelling induced ground displacements, and mechanism $\mathrm{S}$ related to the pile head load redistribution caused by the structure stiffness. Contrasting results between tests where the effects of structural stiffness were considered (test TPSI2) or discounted (test TPGI) enabled the relative contribution of the mechanisms to be studied. For the pile nearest the tunnel, a complex interaction between the two mechanisms occurs, with pile head load reducing because of mechanism S, end-bearing resistance reducing because of mechanism $\mathrm{T}$, and shaft resistance increasing within the mid to upper regions of the pile to satisfy equilibrium. The next pile is less affected by mechanism $\mathrm{T}$ but, because of mechanism $\mathrm{S}$, experiences an increase in head load and shaft resistance, mainly near the pile head. The effects of mechanism $\mathrm{T}$ diminish with distance from the tunnel. However, mechanism $\mathrm{S}$ can still affect the more distant piles; in particular, a decrease in pile head load was observed for the pile most distant from the tunnel.

The effect of tunnel volume loss on the post-tunnelling response of piles (stiffness and capacity) was also evaluated experimentally. Results showed that, generally, the post-tunnelling response of the piles was similar to that of greenfield pile jacking tests (tunnel volume loss not considered). This result suggests that the tunnelling induced soil volumetric strains (contraction in this case) could have an important beneficial effect (countering the detrimental effect of stress relief) in determining the post-tunnelling loading response of piles.

\section{DATA AVAILABILITY STATEMENT}

Some or all data, models, or code that support the findings of this study are available from the corresponding author upon reasonable request. 
$B_{i}=$ The spacing of the building column

$C=$ Depth of cover above the tunnel

$d_{e}=$ Distance between the pile and tunnel (Pile 1)

$d_{p}=$ Diameter of the pile

$D_{t}=$ Diameter of the tunnel $\left(d_{t}\right)$

$D_{50}=$ Average size of the soil particle

$e_{\max }=$ Maximum void ratio

$e_{\text {min }}=$ Minimum void ratio

$E=$ Young's modulus

$G_{s}=$ Specific gravity

$h=$ Distance from the soil horizon mid-point to pile tip

$H_{i}=$ Height of the building storey in prototype scale

$I_{d}=$ Relative density

$K_{0}=$ Static earth pressure coefficient

$L_{p}=$ Pile length, measured from ground surface to pile tip

$p_{i}=$ Initial pile head load

$p_{i}^{\prime}=$ Modified pile head load

$Q_{p}=$ Pile head load

$R=$ Pile radius

$S_{p}=$ Spacing between piles or pile settlement

$V_{l, t}=$ Tunnel volume loss, in \%

$V_{l, t f}=$ Final tunnel volume loss, in \%

$\Delta \sigma_{r}^{\prime}=$ Change in radial effective stress

$\Delta \tau_{a v}=$ Change in average shear stress

$\Delta Q_{p}=$ Change in pile load

$\mu=$ Poisson's ratio

$\sigma_{c s}^{\prime}=$ Critical radial stress

$\sigma_{v}^{\prime}=$ Vertical effective stress

$\sigma_{r}^{\prime}=$ Radial effective stress

$\tau_{a v}=$ Average shear stress

$\tau_{c s}=$ Critical shear stress

$\phi_{c s}^{\prime}=$ Critical state friction angle of soil 


\section{REFERENCES}

Bolton, M. D. (1986). “The strength and dilatancy of sands.” Géotechnique, 36(1), 65-78.

Boulon, M. and Foray, P. (1986). "Physical and numerical simulation of lateral shaft friction along offshore piles in sand." Proceedings of the 3rd International Conference on Numerical methods in Offshore piling, Nantes, France, 127-147.

Bruno, D. (1999). "Dynamic and static load testing of driven piles in sand." Ph.D. thesis, University of Western Australia, University of Western Australia.

Correia, R., James, S. W., Marshall, A. M., Heron, C. M., and Korposh, S. (2016). "Interrogation of fibre Bragg gratings through a fibre optic rotary joint on a geotechnical centrifuge." 6th European Workshop on Optical Fibre Sensors (EWOFS'2016), Vol. 99162B, Limerick, Ireland, 1-4.

DeJong, J. T., Randolph, M. F., and White, D. J. (2003). "Interface load transfer degradation during cyclic loading: a microscale investigation.” Soils and foundations, 43(4), 81-93.

Evgin, E. and Fakharian, K. (1997). "Effect of stress paths on the behaviour of sand steel interfaces." Canadian geotechnical journal, 33(6), 853-865.

Farrell, R. P. (2010). "Tunnelling in sands and the response of buildings." Ph.D. thesis, University of Cambridge, University of Cambridge.

Franza, A. (2016). "Tunnelling and its effects on piles and piled structures." Ph.D. thesis, University of Nottingham, University of Nottingham.

Franza, A., Idinyang, S., Heron, C., Marshall, A. M., and Abdelatif, A. (2016). "Development of a coupled centrifuge-numerical model to study soil-structure interaction problems." Proceedings of the 3rd European Conference on Physical Modelling in Geotechnics (Eurofuge 2016), 135-140.

Franza, A. and Marshall, A. M. (2018). "Centrifuge and real-time hybrid testing of tunneling beneath piles and piled buildings." Journal of Geotechnical and Geoenvironmental Engineering, 145(3), 04018110.

Franza, A., Marshall, A. M., and Zhou, B. (2019). "Greenfield tunnelling in sands: the effects of soil density and relative depth." Geotechnique, 69(4), 297-307.

Gulvanessian, H., Formichi, P., and Calgaro, J. A. (2009). Designers' Guide to Eurocode 1: Actions on Buildings: EN1991-1-1 and-1-3 TO-1-7. Thomas Telford Ltd.

Hibbitt, K. (2002). ABAQUS/Explicit User's Manual: Version 6.3. Hibbit, Karlsonn \& Sorensen.

Idinyang, S., Franza, A., Heron, C., and Marshall, A. M. (2018). "Real-time data coupling for hybrid testing in a geotechnical centrifuge." International Journal of Physical Modelling in Geotechnics, 1-13.

Jacobsz, S. W. (2003). "The effects of tunnelling on piled foundations." Ph.D. thesis, University of Cambridge, University of Cambridge.

Kelly, R. (2001). "Development of a large diameter ring shear apparatus and its use." Ph.D. thesis, The University of Sydney, The University of Sydney. 
Kersey, A. D., Davis, M. A., Patrick, H. J., LeBlanc, M., Koo, K., Askins, C., Putnam, M., and Friebele, E. J. (1997). "Fiber grating sensors." Journal of lightwave technology, 15(8), 1442-1463.

Klotz, E. and Coop, M. (2001). "An investigation of the effect of soil state on the capacity of driven piles in sands." Géotechnique, 51(9), 733-751.

Lee, C. J. and Chiang, K. H. (2007). "Responses of single piles to tunneling-induced soil movements in sandy ground." Canadian Geotechnical Journal, 44(10), 1224-1241.

Lehane, B., Gaudin, C., and Schneider, J. (2005). "Scale effects on tension capacity for rough piles buried in dense sand." Géotechnique, 55(10), 709-719.

Lehane, B. M., Jardine, R., Bond, A. J., and Frank, R. (1993). "Mechanisms of shaft friction in sand from instrumented pile tests." Journal of Geotechnical Engineering, 119(1), 19-35.

Loganathan, N., Poulos, H. G., and Stewart, D. P. (2000). "Centrifuge model testing of tunnellinginduced ground and pile deformations." Geotechnique, 50(3), 283-294.

Marshall, A. M. (2009). "Tunnelling in sand and its effect on pipelines and piles." Ph.D. thesis, University of Cambridge, University of Cambridge.

Marshall, A. M. (2012). “Tunnel-pile interaction analysis using cavity expansion methods." Journal of Geotechnical and Geoenvironmental Engineering, 138(10), 1237-1246.

Marshall, A. M., Franza, A., and Jacobsz, S. W. (2020). "An assessment of the post-tunneling safety factor of piles under drained soil conditions." ASCE Journal of Geotechnical and Geoenvironmental Engineering, In Press.

Marshall, A. M. and Haji, T. K. (2015). "An analytical study of tunnel-pile interaction.” Tunnelling and Underground Space Technology, 45, 43-51.

Marshall, A. M. and Mair, R. J. (2011). "Tunneling beneath driven or jacked end-bearing piles in sand." Canadian Geotechnical Journal, 48(12), 1757-1771.

Mortara, G., Ferrara, D., and Fotia, G. (2010). "Simple model for the cyclic behavior of smooth sand-steel interfaces." Journal of geotechnical and geoenvironmental engineering, 136(7), 10041009.

Moyo, P., Brownjohn, J. M. W., Suresh, R., and Tjin, S. C. (2005). "Development of fiber bragg grating sensors for monitoring civil infrastructure." Engineering structures, 27(12), 1828-1834.

Nicola, A. D. and Randolph, M. (1999). "Centrifuge modelling of pipe piles in sand under axial loads." Géotechnique, 49(3), 295-318.

Porcino, D., Fioravante, V., Ghionna, V. N., and Pedroni, S. (2003). "Interface behavior of sands from constant normal stiffness direct shear tests." Geotechnical Testing Journal, 26(3), 289-301.

Song, G. (2019). "The use of protective structures to reduce tunnelling induced damage to buildings." Ph.D. thesis, University of Nottingham, University of Nottingham.

Song, G. and Marshall, A. M. (2020). "Centrifuge modelling of tunnelling induced ground displacements: pressure and displacement control tunnels." Tunnelling and Underground Space Technology, 103. 
Song, G., Marshall, A. M., and Heron, C. (2018). "A mechanical displacement control model tunnel for simulating eccentric ground loss in the centrifuge." 9th International Conference of Physical Modelling in Geotechnics: ICPMG.

Song, G., Marshall, A. M., and Heron, C. M. (2019). "Load redistribution of piles affected by tunnelling: hybrid centrifuge tests using fibre Bragg grating." Proceedings of the XVII ECSMGE2019, Reykjavik, Iceland.

Stanier, S. A., Blaber, J., Take, W. A., and White, D. (2015). "Improved image-based deformation measurement for geotechnical applications." Canadian Geotechnical Journal, 53(5), 727-739.

Tabucanon, J. T., Airey, D. W., and Poulos, H. G. (1995). "Pile skin friction in sands from constant normal stiffness tests." Geotechnical Testing Journal, 18(3), 350-364.

Vorster, T. E. B. (2006). "The effects of tunnelling on buried pipes." Ph.D. thesis, University of Cambridge, University of Cambridge.

White, D. and Lehane, B. (2004). "Friction fatigue on displacement piles in sand." Géotechnique, 54(10), 645-658.

White, D. J. and Bolton, M. D. (2004). "Displacement and strain paths during plane-strain model pile installation in sand." Géotechnique, 54(6), 375-397.

Zhou, B. (2015). "Tunnelling-induced ground displacements in sand." Ph.D. thesis, University of Nottingham, University of Nottingham. 
CAPTION OF TABLES

List of Tables 
TABLE 1. Summary of the centrifuge tests performed at $80 \mathrm{~g}$

\begin{tabular}{lll}
\hline Test label & Ultimate tunnel volume loss & Description \\
\hline PJ & NA & Pile jacking \\
TPGI & $V_{l, t} \approx 3.2 \%$ & No connected structure \\
TPSI1 & $V_{l, t} \approx 2.2 \%$ & Structure connected \\
TPSI2 & $V_{l, t} \approx 3.2 \%$ & Structure connected \\
TPSI3 & $V_{l, t} \approx 2.8 \%$ & Structure connected \\
\hline
\end{tabular}




\section{CAPTION OF FIGURES}

\section{List of Figures}

1 Test layout in model scale: (a) pile jacking test, and (b) tunnelling next to piled

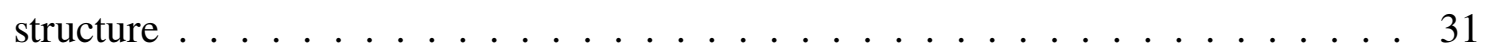

2 CCNM simulation process for a framed building with a pile foundation . . . . . . 31

3 Schematic diagram of FBG sensor system within NCG centrifuge . . . . . . . . 32

4 Axial force along the pile after centrifuge spin-up . . . . . . . . . . . 33

5 After centrifuge spin-up: (a) soil and pile settlements for test TPSI3; (b) illustration of the pile and soil settlements, (c) indicative profile of axial force along the pile due to soil-pile interaction $\ldots \ldots \ldots \ldots$

6 Vertical and radial effective stress profile after centrifuge spin-up; data from Jacobsz

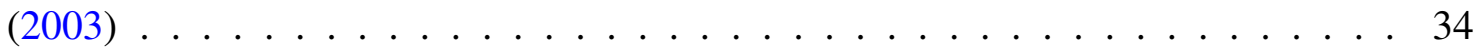

7 Stationary radial effective stress after centrifuge spin-up . . . . . . . . . . . . . 34

$8 \tau_{a v}$ versus $\sigma_{r}^{\prime}$ after centrifuge spin-up for tests PJ, TPGI, TPSI1, 2 and $3 \ldots 35$

9 Pile jacking $(\mathrm{PJ})$ tests: average shaft resistance versus pile settlement and estimated

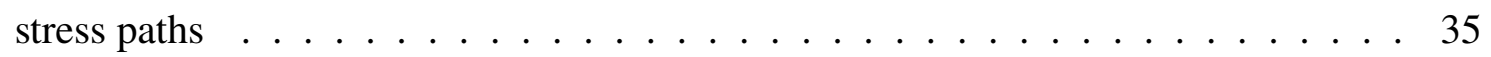

10 Pile jacking (PJ) tests: stationary radial stress $\sigma_{r}^{\prime}$ versus critical state radial stress $\sigma_{c s}^{\prime} 36$

11 Pile jacking (PJ) test: (a) axial load along the pile, (b) development of pile head load, shaft resistance and end bearing load with pile settlement . . . . . . . . . . 37

12 Axial force along piles before and after pile loading in test TPSI $\ldots$. . . . . . . 38

13 Average shear stress $\tau_{a v}$ development during pile loading for piles in TPGI and

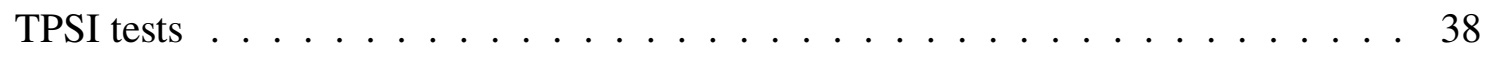

14 Pile head load versus tunnel volume loss $V_{l, t}$ for TPGI and TPSI tests . . . . . . . 39

15 Axial force along piles before and after tunnel volume loss for tests TPGI and TPSI2 40

16 Change in average shear stress $\tau_{a v}$ with tunnel volume loss $V_{l, t}$ for tests TPGI and

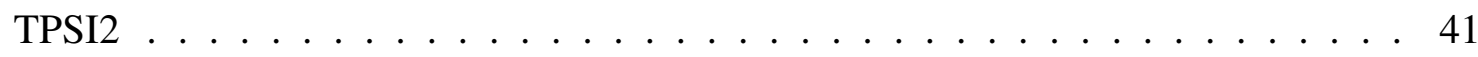


17 Average shear stress $\tau_{a v}$ for soil horizons $h / R=5.1,14.9$, and 21.8 during post-

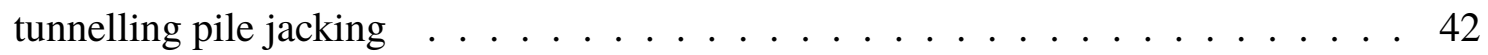

18 Critical state shear stress $\tau_{c s}$ and pile load capacity versus $V_{l, t f} \ldots \ldots$. . . . . 43

19 Post-tunnelling pile jacking for test TPSI2 and PJ: (a) Pile head load versus settlement, (b) Pile head load versus global stiffness . . . . . . . . . . . . . . . 43 


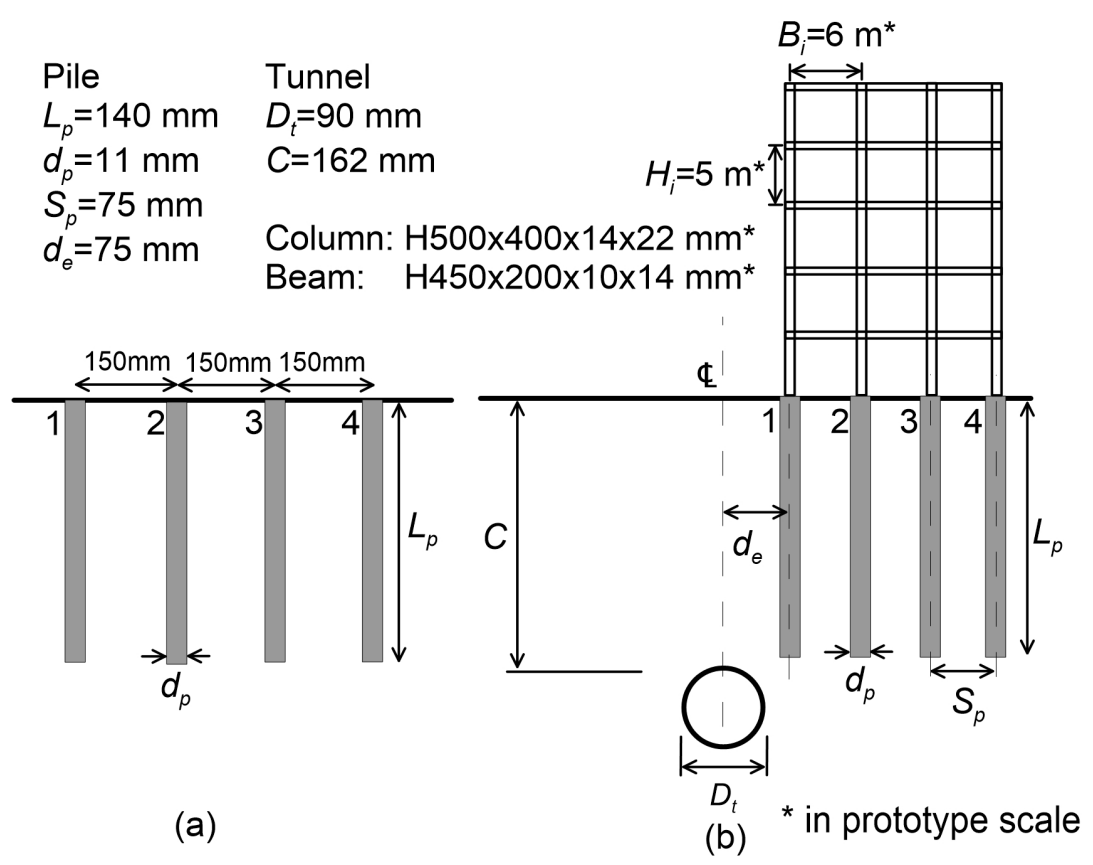

Fig. 1. Test layout in model scale: (a) pile jacking test, and (b) tunnelling next to piled structure

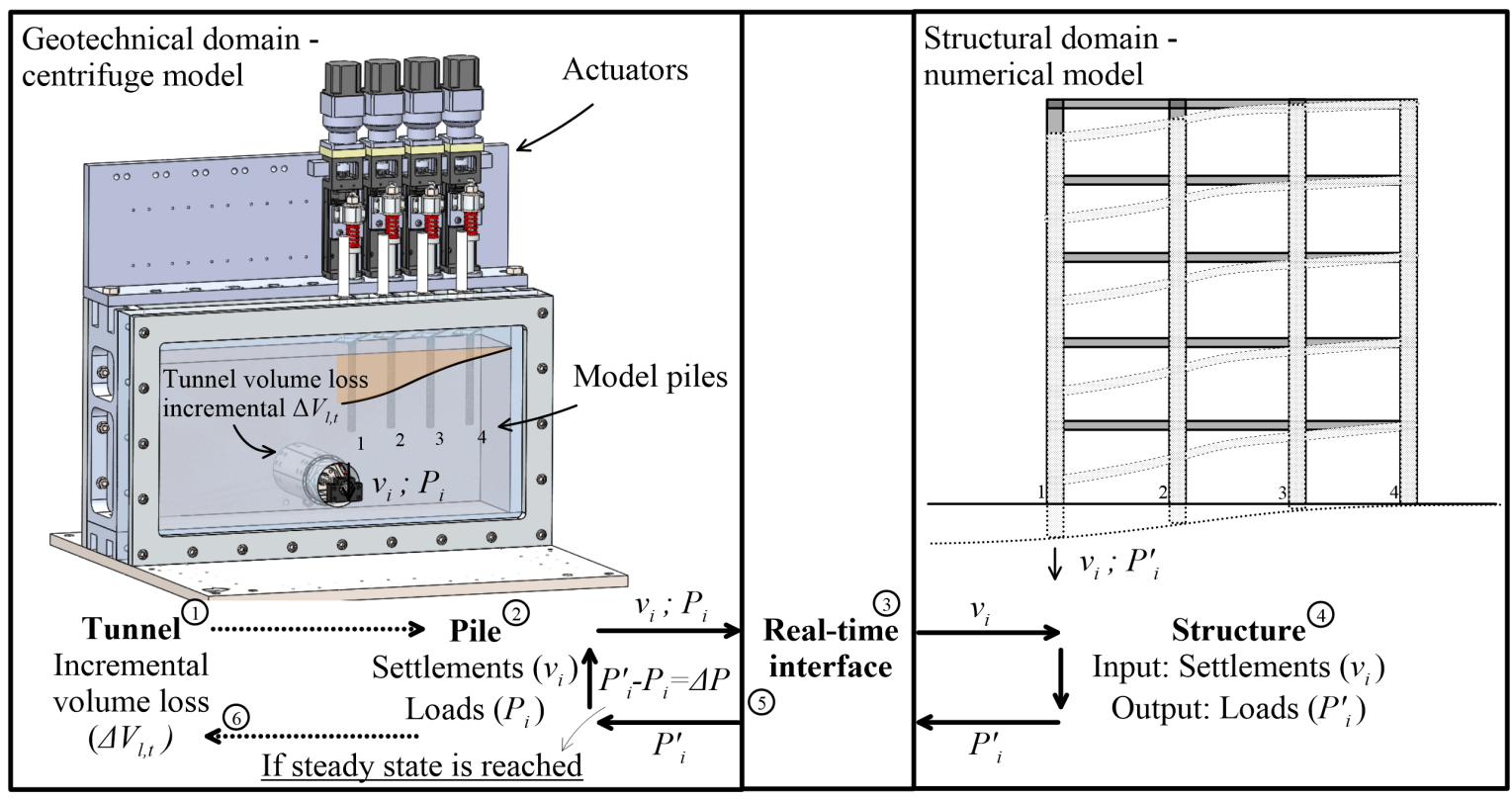

Fig. 2. CCNM simulation process for a framed building with a pile foundation 


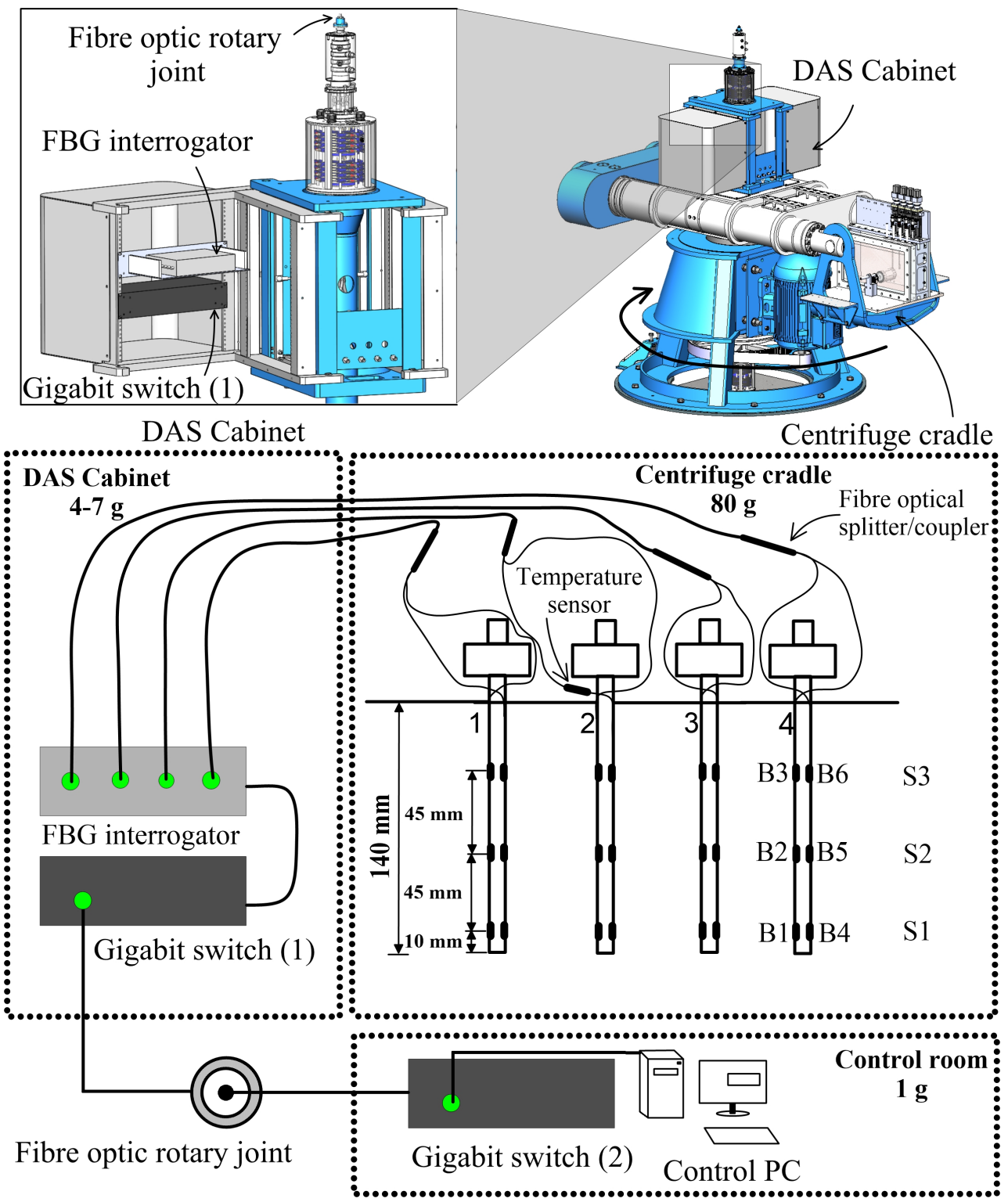

Fig. 3. Schematic diagram of FBG sensor system within NCG centrifuge 


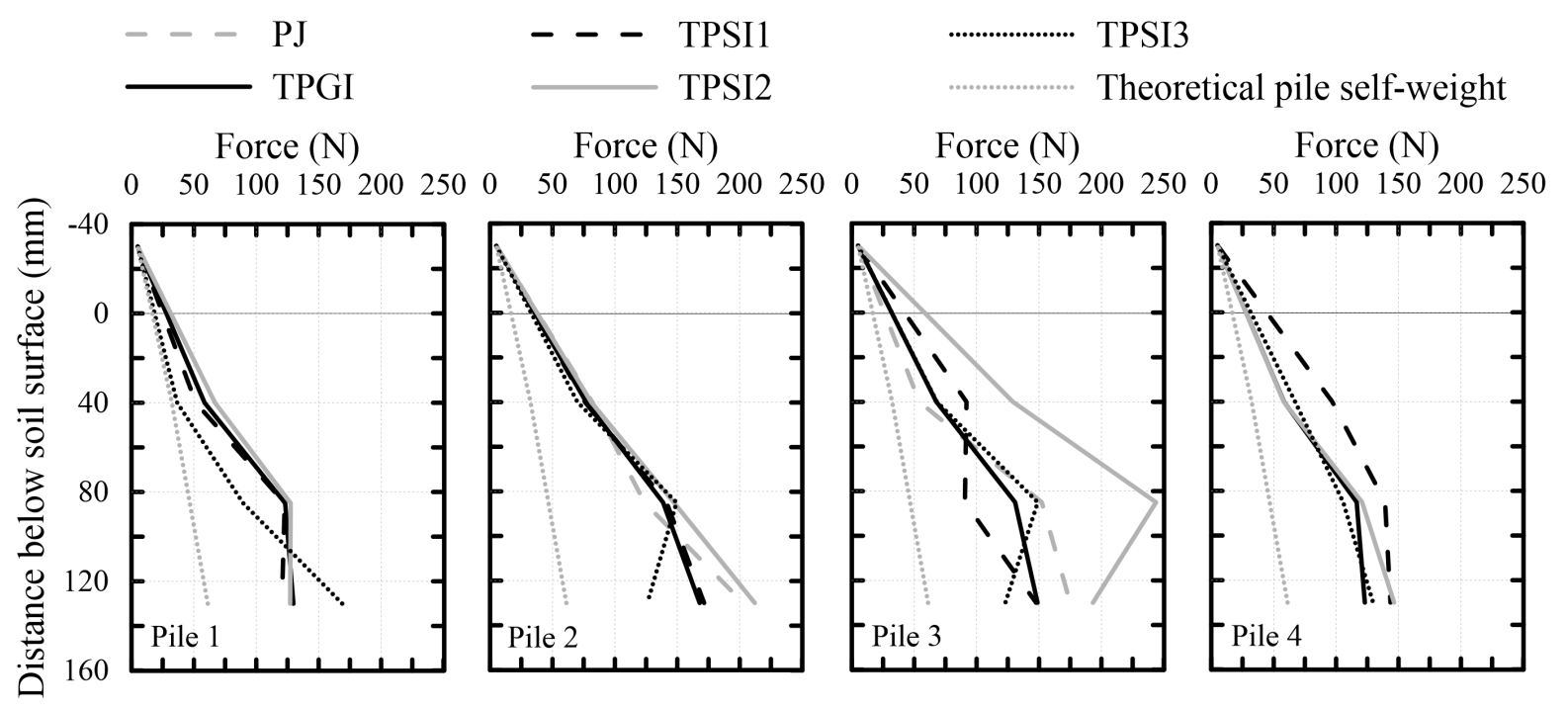

Fig. 4. Axial force along the pile after centrifuge spin-up

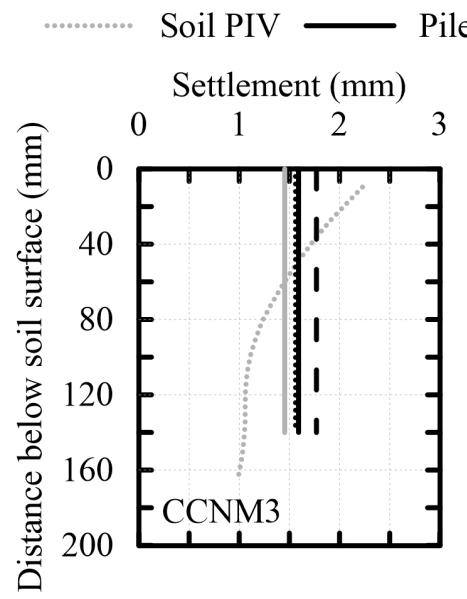

(a)

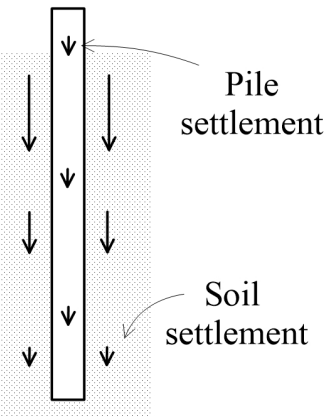

(b)

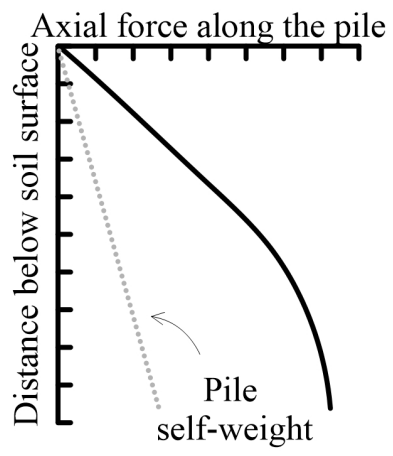

(c)

Fig. 5. After centrifuge spin-up: (a) soil and pile settlements for test TPSI3; (b) illustration of the pile and soil settlements, (c) indicative profile of axial force along the pile due to soil-pile interaction 


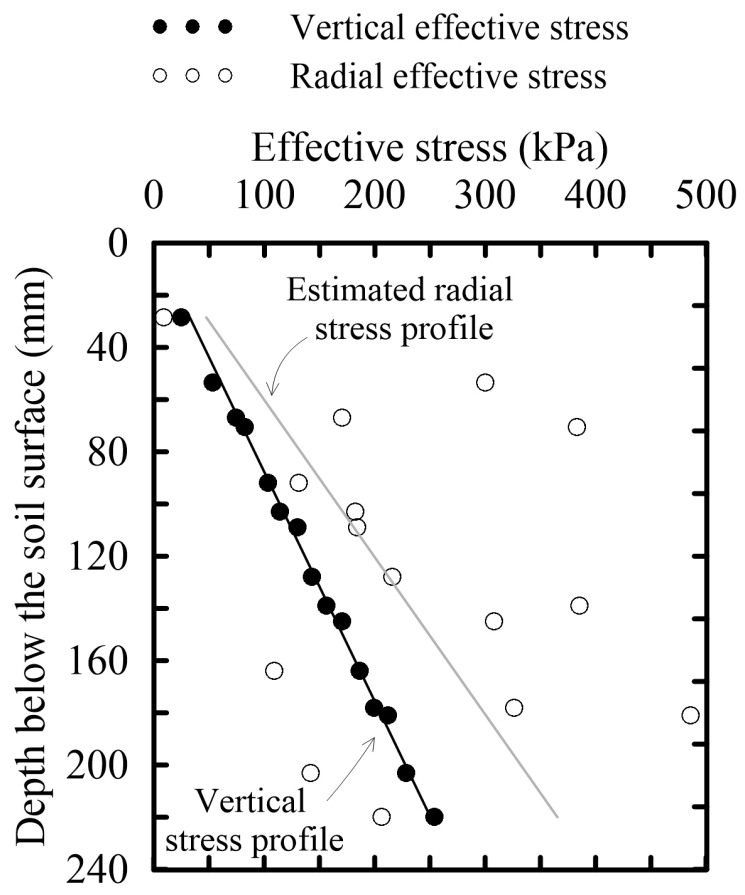

Fig. 6. Vertical and radial effective stress profile after centrifuge spin-up; data from Jacobsz (2003)

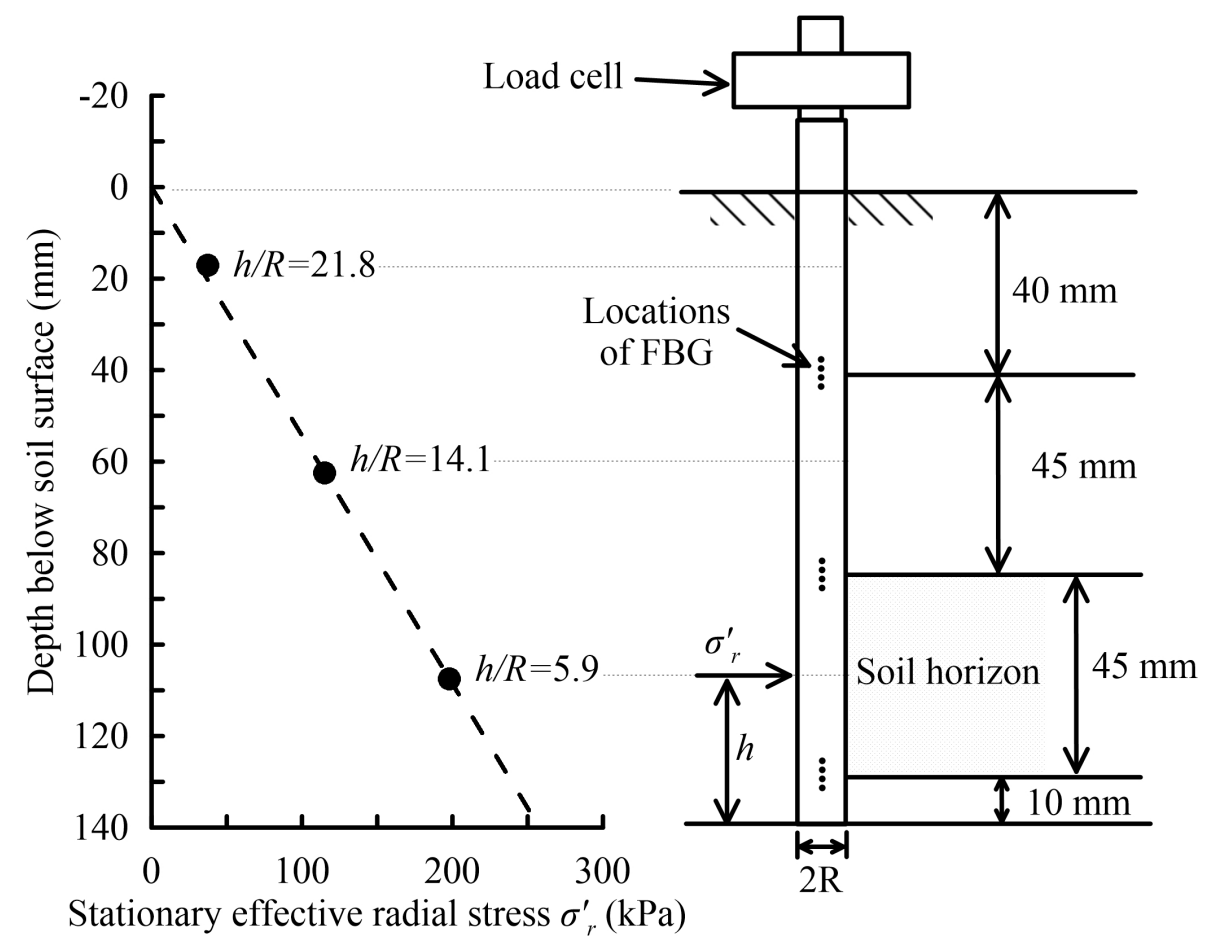

Fig. 7. Stationary radial effective stress after centrifuge spin-up 


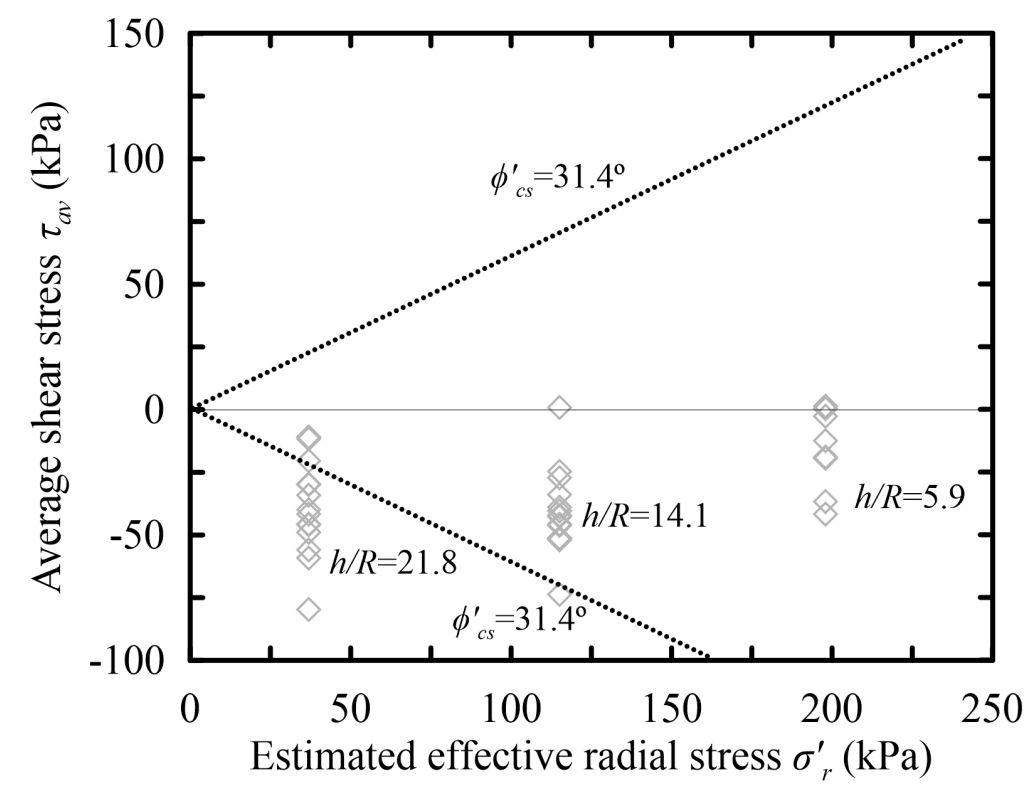

Fig. 8. $\tau_{a v}$ versus $\sigma_{r}^{\prime}$ after centrifuge spin-up for tests PJ, TPGI, TPSI1-3
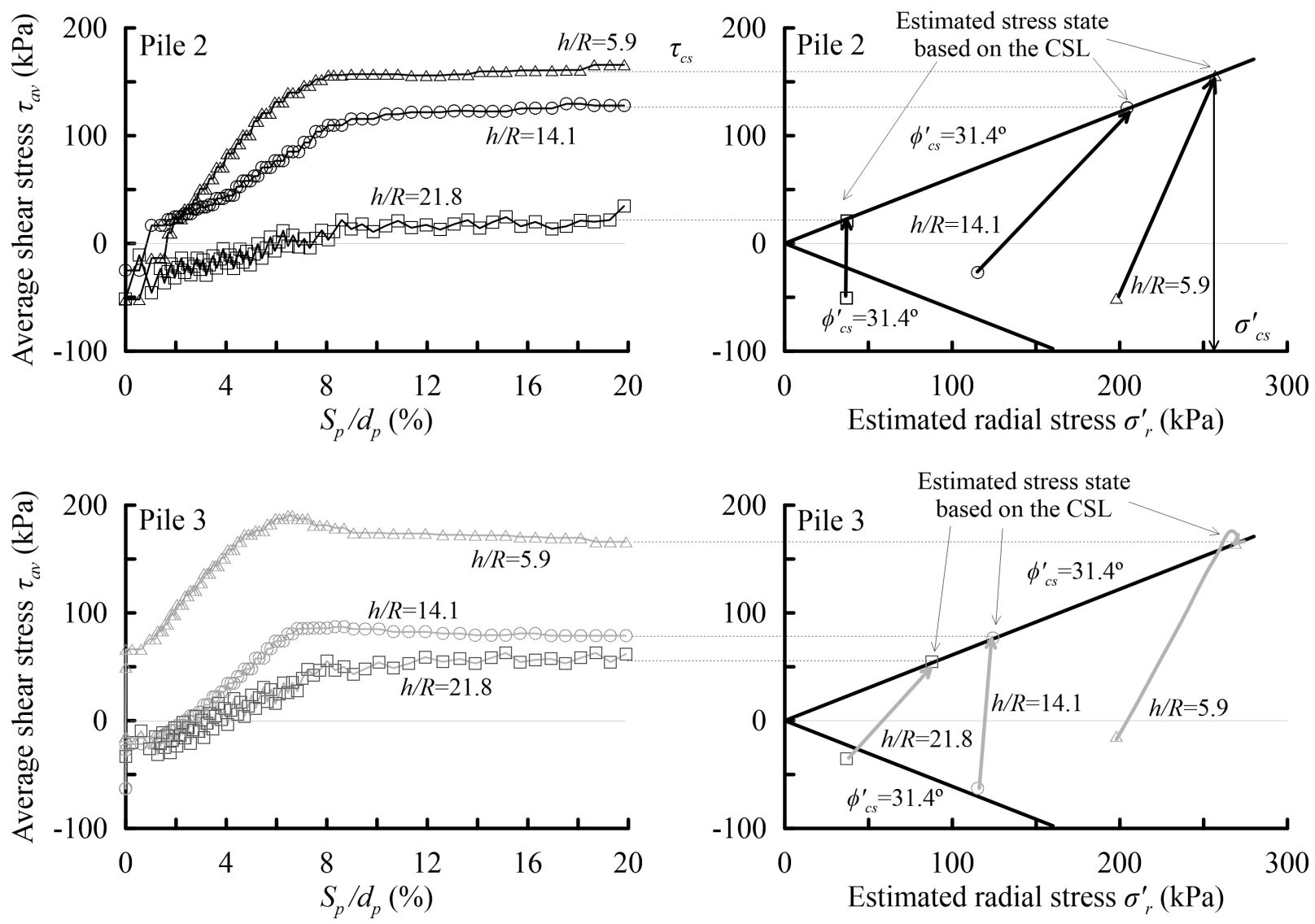

Fig. 9. Pile jacking (PJ) tests: average shaft resistance versus pile settlement and estimated stress paths 


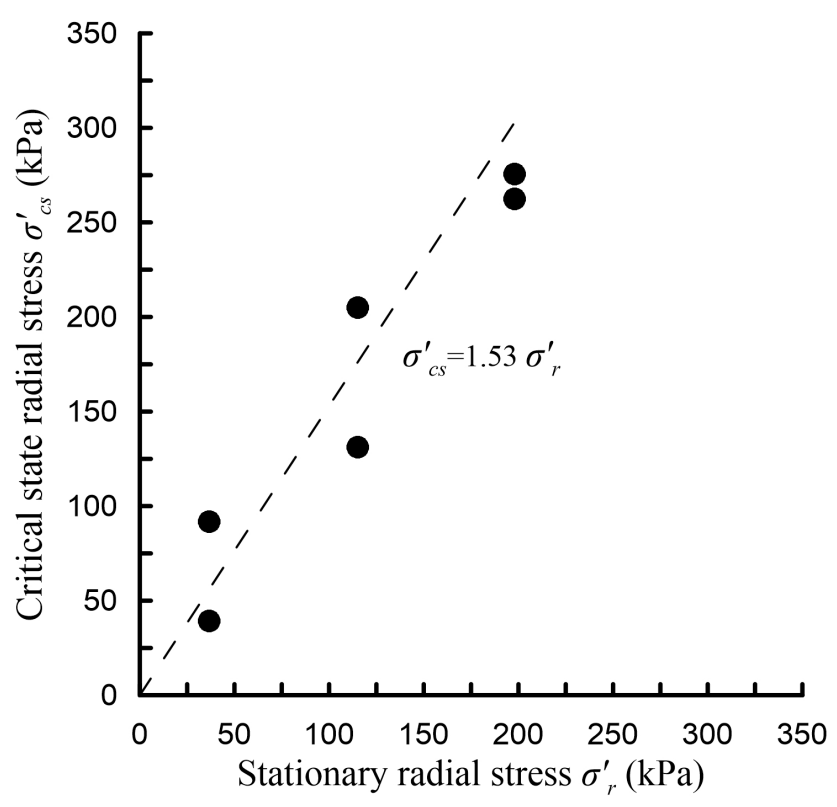

Fig. 10. Pile jacking (PJ) tests: stationary radial stress $\sigma_{r}^{\prime}$ versus critical state radial stress $\sigma_{c s}^{\prime}$ 


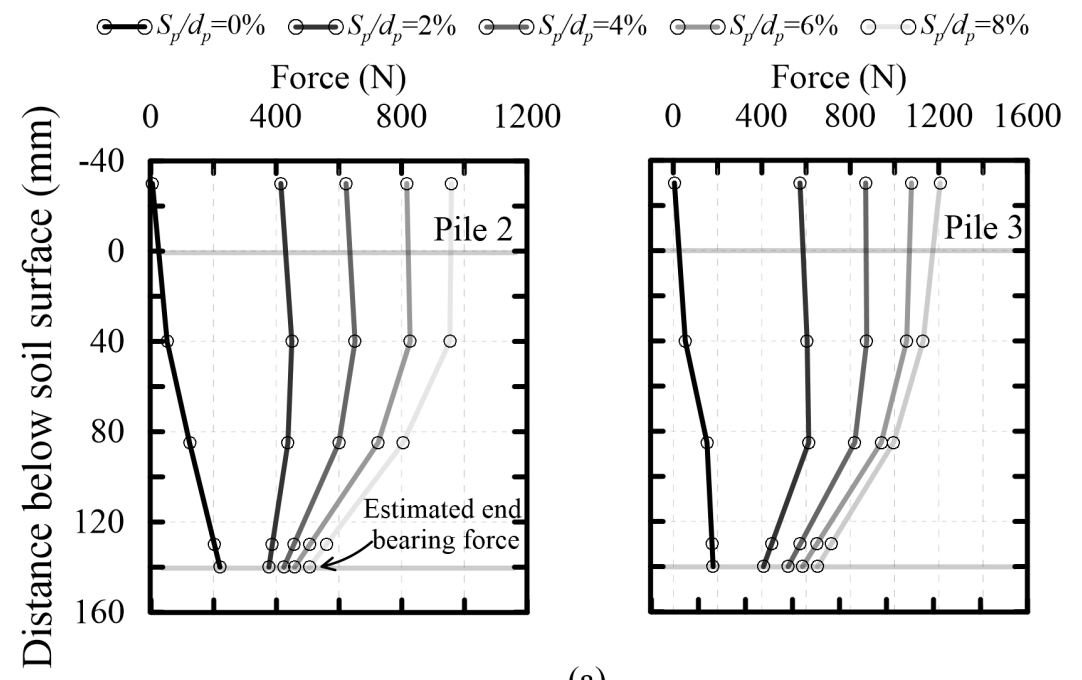

(a)

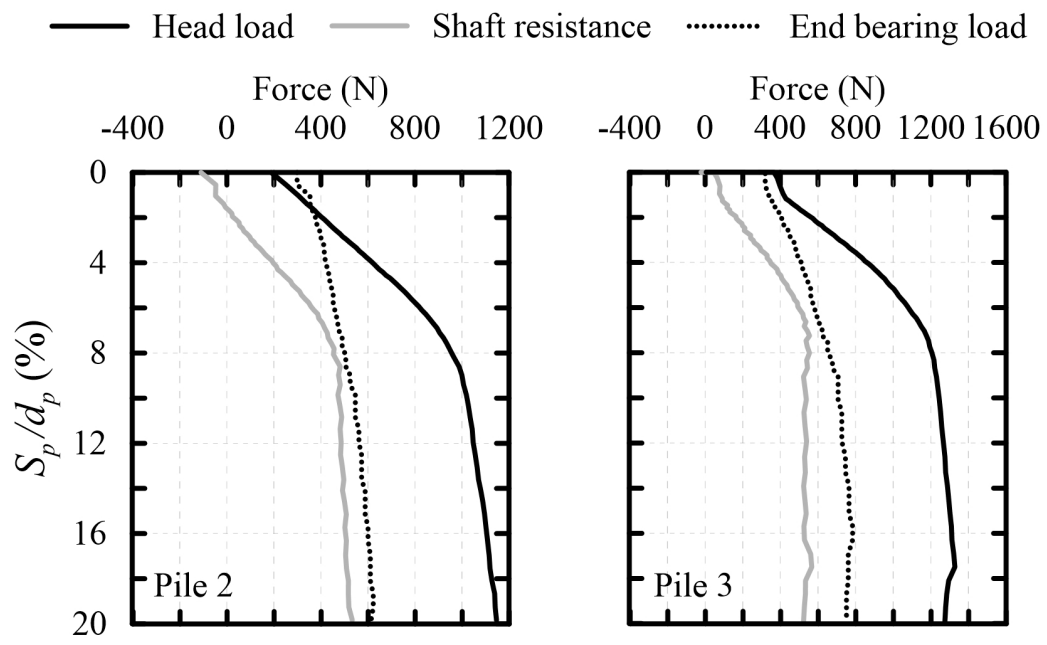

(b)

Fig. 11. Pile jacking (PJ) test: (a) axial load along the pile, (b) development of pile head load, shaft resistance and end bearing load with pile settlement 


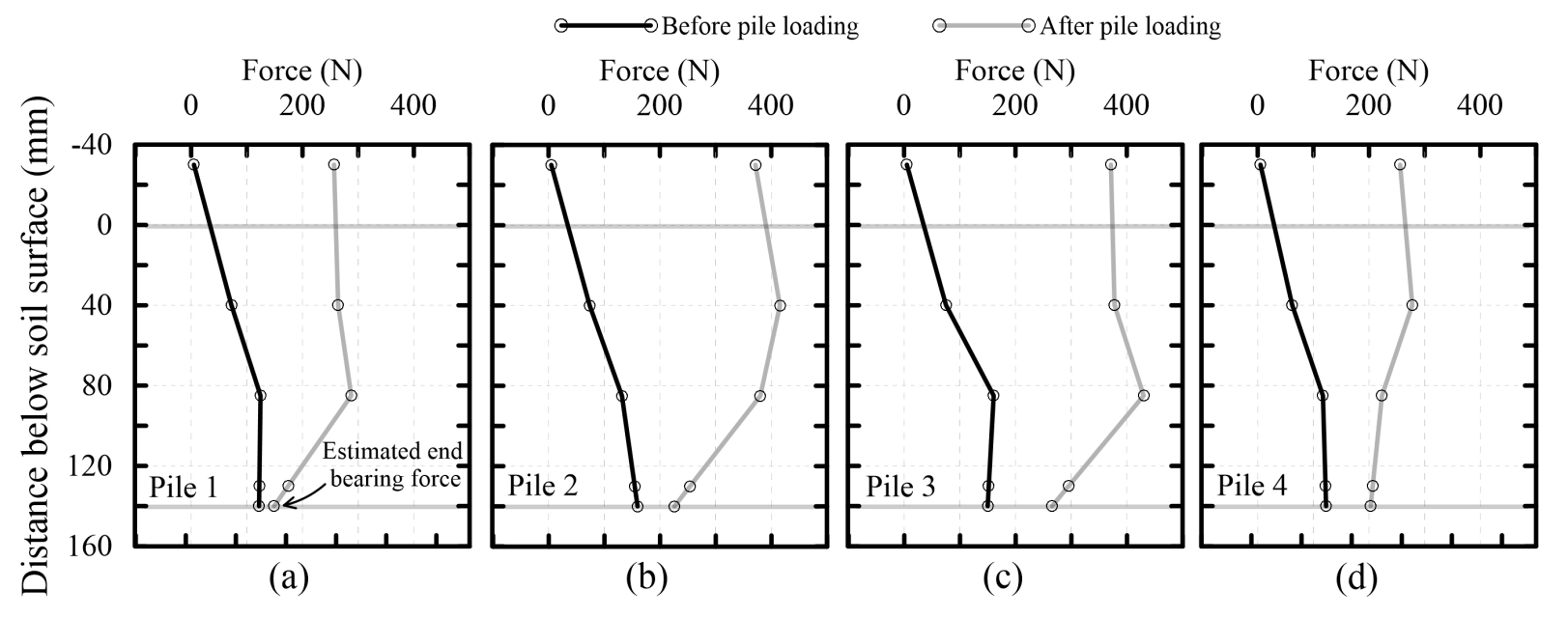

Fig. 12. Axial force along piles before and after pile loading in test TPSI2

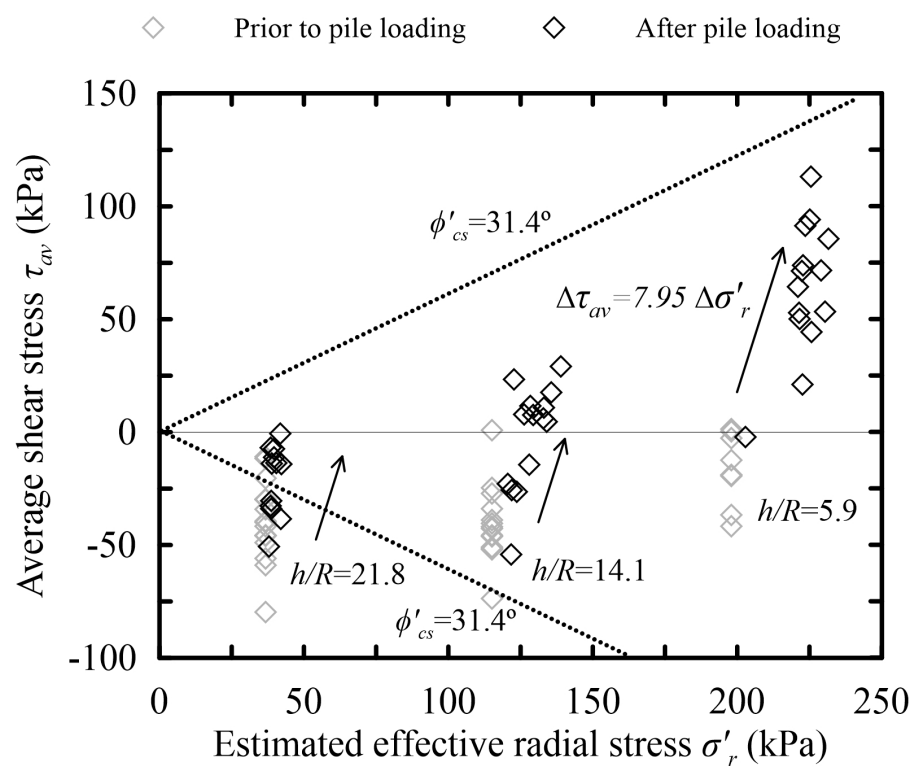

Fig. 13. Average shear stress $\tau_{a v}$ development during pile loading for piles in TPGI and TPSI tests 

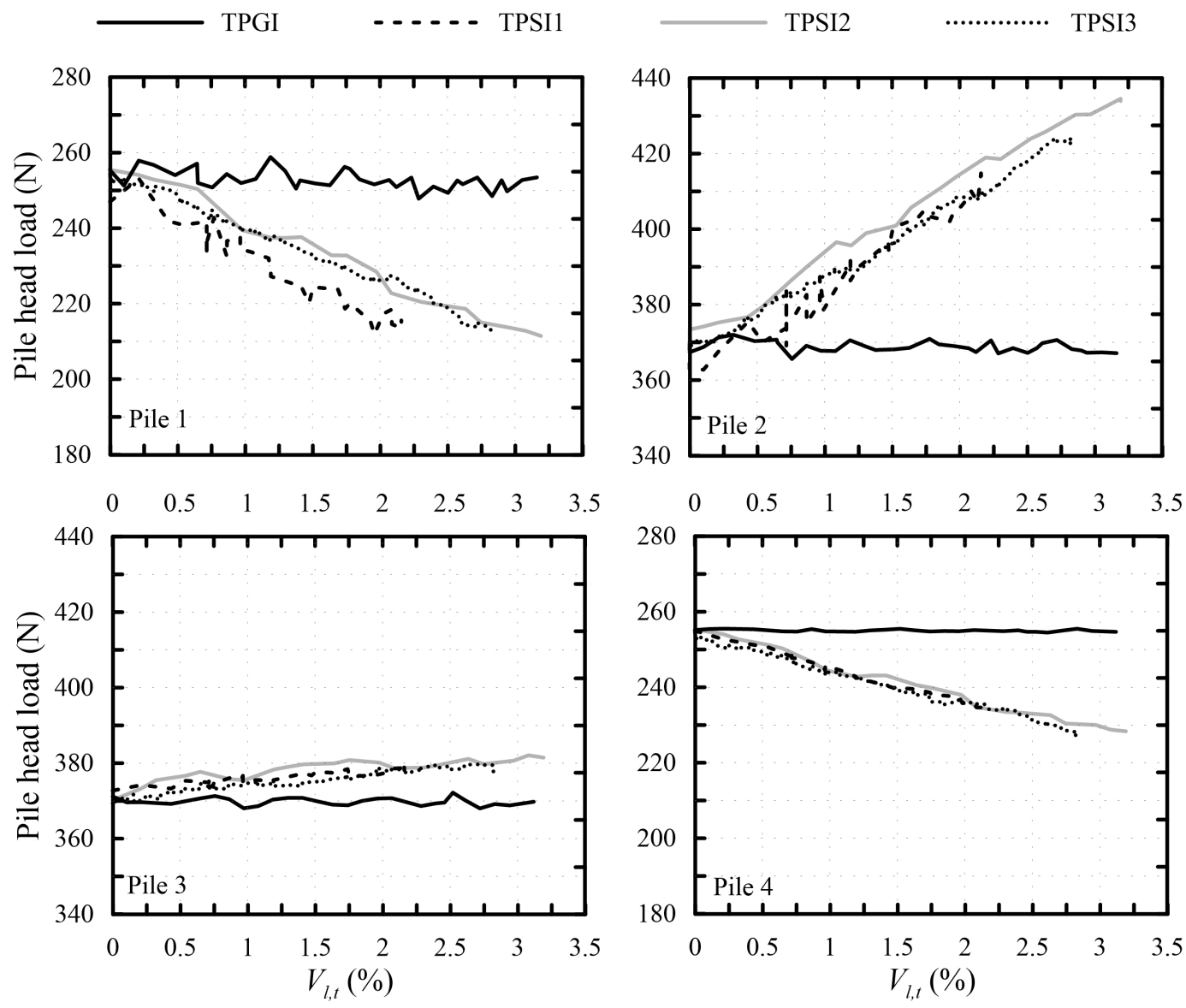

Fig. 14. Pile head load versus tunnel volume loss $V_{l, t}$ for TPGI and TPSI tests 


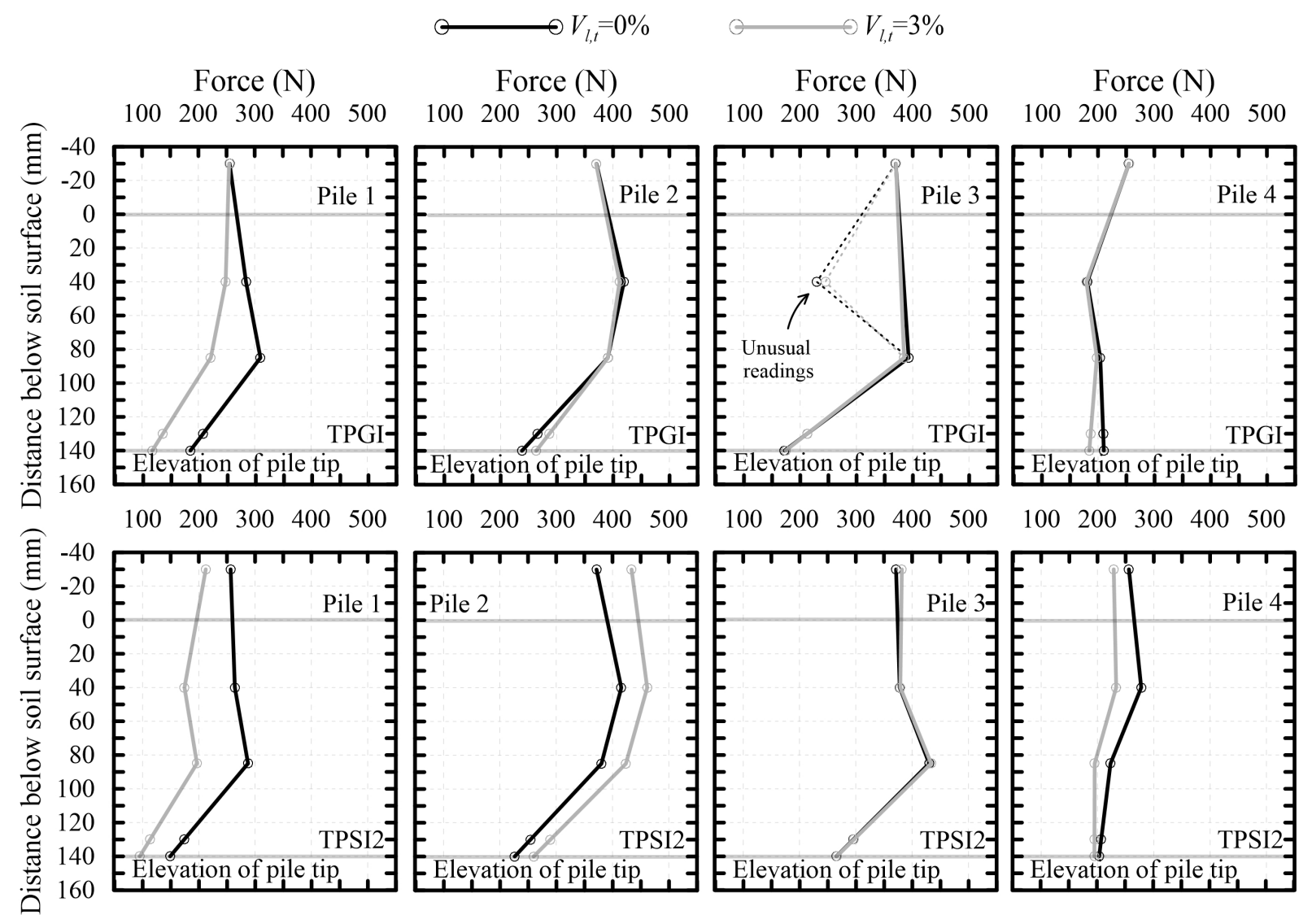

Fig. 15. Axial force along piles before and after tunnel volume loss for tests TPGI and TPSI2 


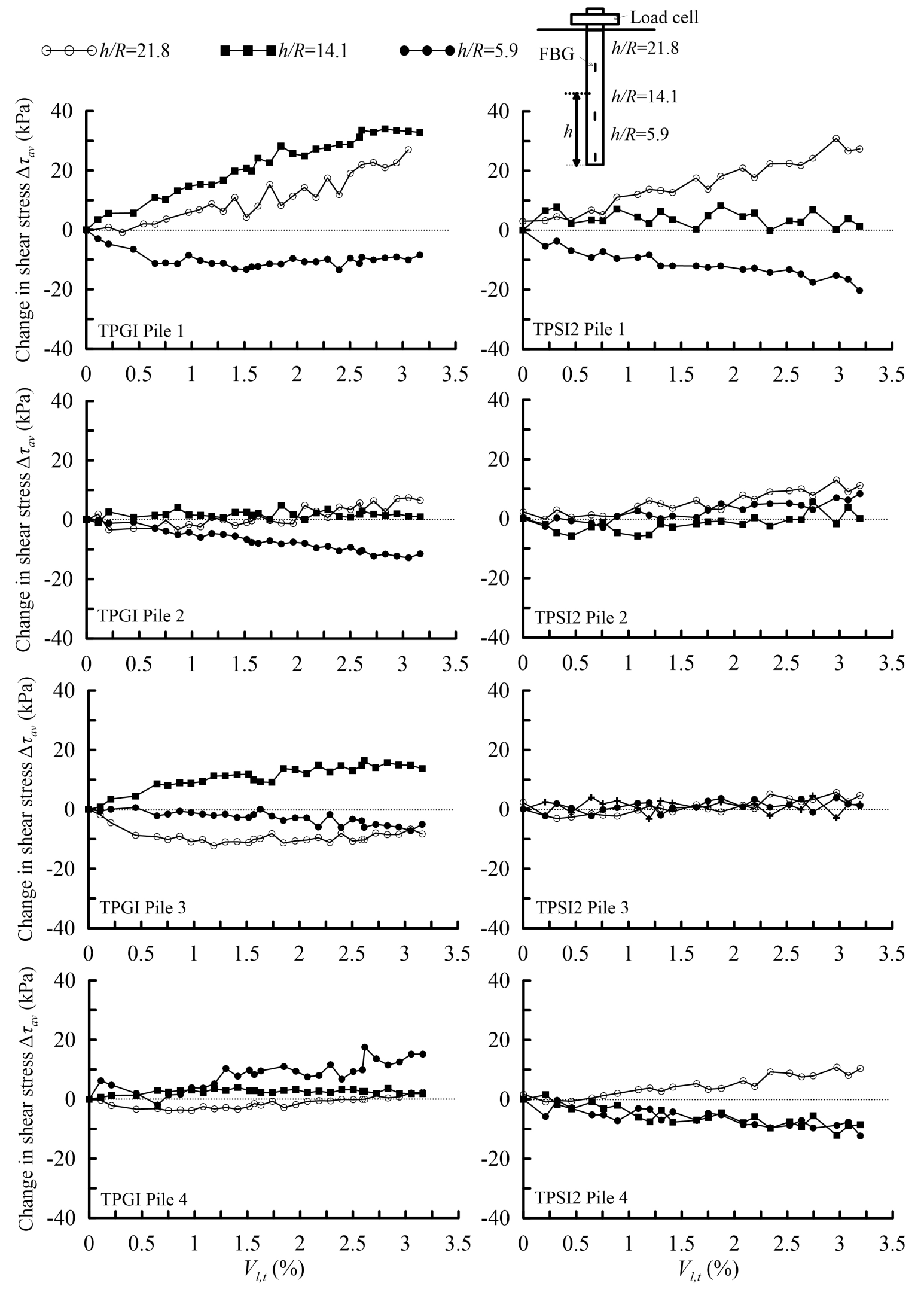

Fig. 16. Change in average shear stress $\tau_{a v}$ with tunnel volume loss $V_{l, t}$ for tests TPGI and TPSI2 

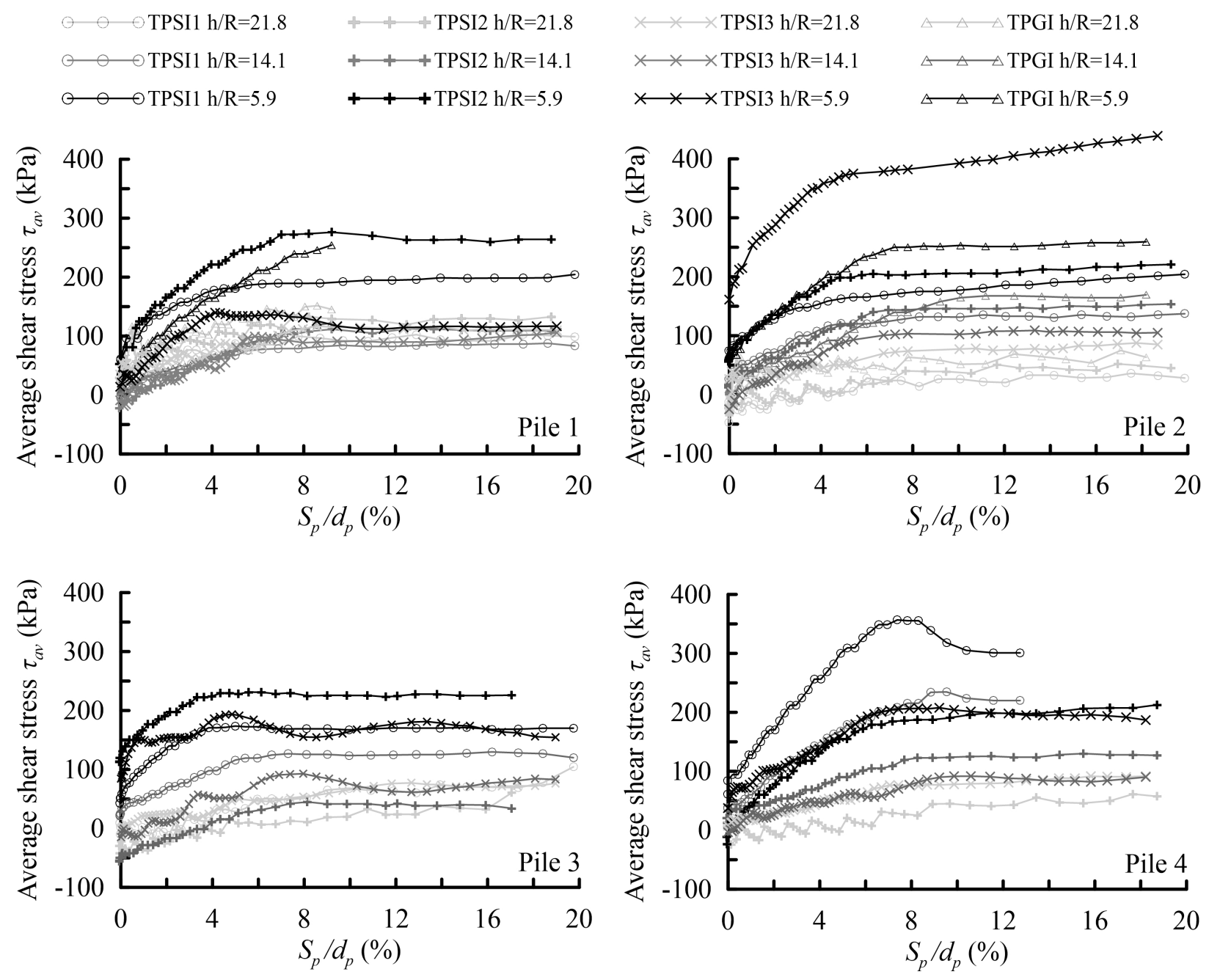

Fig. 17. Average shear stress $\tau_{a v}$ for soil horizons $h / R=5.1,14.9$, and 21.8 during post-tunnelling pile jacking 

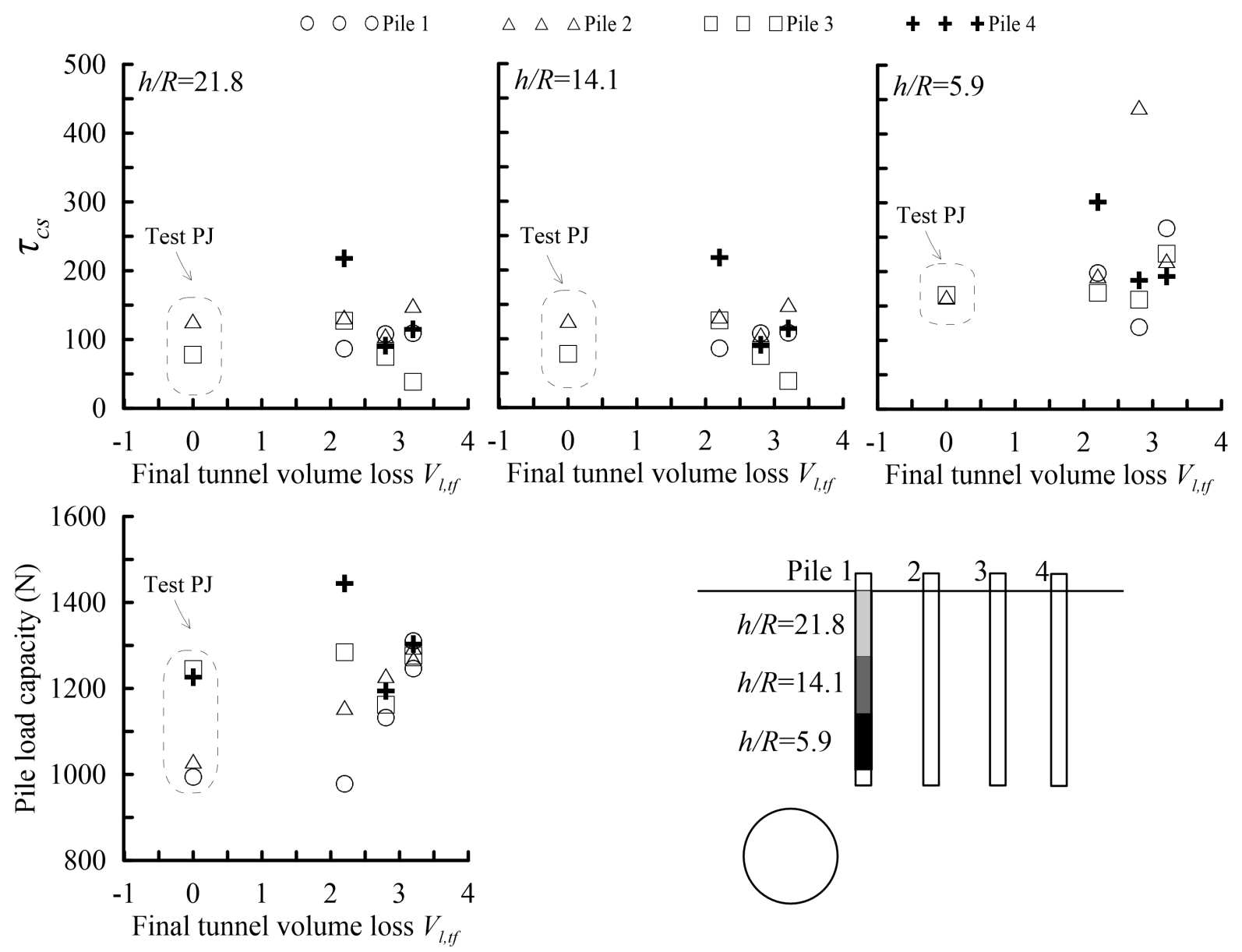

Final tunnel volume loss $V_{l, f f} \quad$ Final tunnel volume loss $V_{l, t f}$

Fig. 18. Critical state shear stress $\tau_{c s}$ and pile load capacity versus $V_{l, t f}$

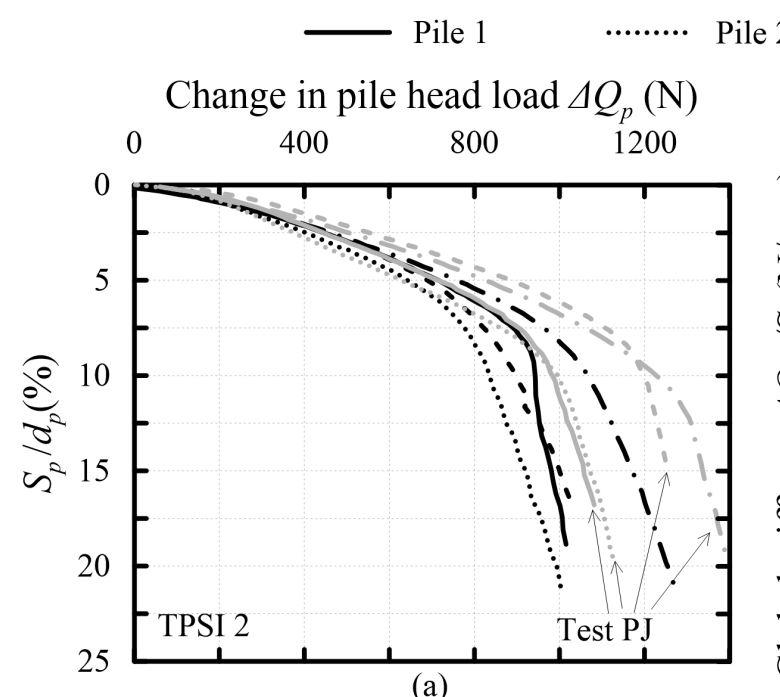

2

-... Pile $3 \quad-\cdot-$ Pile 4

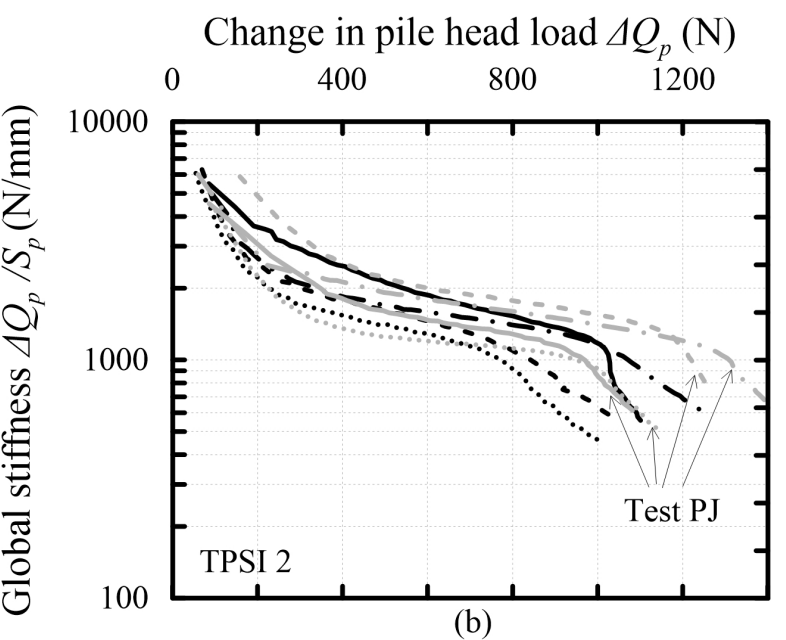

Fig. 19. Post-tunnelling pile jacking for test TPSI 2 and PJ: (a) Pile head load versus settlement, (b) Pile head load versus global stiffness 